\title{
Fluorine Plasma Treatments of Poly(propylene) Films, 2 - Modeling Reaction Mechanisms and Scaling ${ }^{\mathrm{a}}$
}

\author{
Yang Yang, Mark Strobel, Seth Kirk, Mark J. Kushner*
}

The surface properties of commodity hydrocarbon polymers such as poly(propylene) (PP) can be modified by functionalization with plasma-generated radicals and ions. For example, affixing fluorine to a hydrocarbon surface lowers surface energy and increases hydrophobicity. One such process is treatment of PP films in low-pressure, capacitively coupled plasmas (CCPs) sustained in $\mathrm{F}_{2}$-containing gas mixtures. $\mathrm{F}$ atoms produced in the plasma abstract $\mathrm{H}$ atoms from the hydrocarbon and passivate the resulting alkyl sites producing $\mathrm{C}-\mathrm{F}_{n}$ sites. Energetic ion and photon fluxes sputter and initiate crosslinking. In this paper, the plasma fluorination of $\mathrm{PP}$ in a CCP sustained in $\mathrm{Ar} / \mathrm{F}_{2}$ is discussed with results from a two-dimensional plasma hydrodynamics model. The surface reaction mechanism includes a hierarchy of $\mathrm{H}$ abstraction and $\mathrm{F} / \mathrm{F}_{2}$ passivation reactions, as well as crosslinking, and ion and photon-activated processes. Predictions for surface composition were compared to experiments. We found that the lack of total fluorination with long plasma exposure is likely caused by crosslinking, which creates C-C bonds that might otherwise be passivated by $\mathrm{F}$ atoms. Increasing steric hindrances as fluorination proceeds also contribute to lower $\mathrm{F} / \mathrm{C}$ ratios.

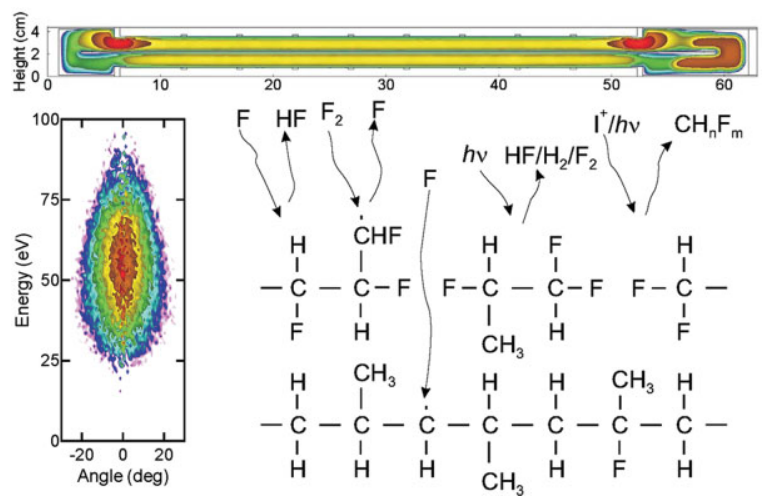

M. J. Kushner

Department of Electrical Engineering and Computer Science, University of Michigan, 1301 Beal Avenue, Ann Arbor, Michigan 48109, USA

E-mail: mjkush@umich.edu

Y. Yang

Department of Electrical and Computer Engineering, lowa State University, Ames, lowa 50011, USA

M. Strobel, S. Kirk

Corporate Research Process Laboratory, 3M Company, 3M Center, St. Paul, Minnesota 55144, USA

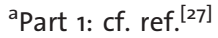

\section{Introduction}

The fluorination of the surface layers of hydrocarbon polymers modifies the wetting properties of the polymer by decreasing the surface energy and increasing hydrophobicity. ${ }^{[1-3]}$ The fluorination process usually entails the removal of hydrogen from the hydrocarbon polymer backbone, forming an alkyl site, and the passivation of the alkyl site with a fluorine atom. ${ }^{[4]}$ As most hydrocarbon polymers are heat sensitive, it is desirable for the fluorination to take place at low temperatures. As such, low-pressure, non-equilibrium plasmas are attractive options for this surface treatment.

In low-pressure plasmas sustained in fluorine-containing feedstock gases, electron-impact reactions (mainly by dissociative excitation or attachment) produce 
fluorine-containing radicals at low ambient gas and surface temperatures. These radicals can both abstract hydrogen from the polymer surface layers, producing alkyl sites, and passivate those sites with fluorine atoms. Compared to fluorination by exposure to elemental fluorine gas at atmospheric pressure, low-pressure plasma fluorination proceeds more rapidly and more controllably. Significant fluorination of hydrocarbon polymers can occur in only a few seconds in low-pressure plasmas. ${ }^{[5,6]}$ This fluorination typically occurs to a depth of at most $10 \mathrm{~nm}$ thereby leaving the bulk properties largely unchanged. ${ }^{[7]}$ An added feature of plasma fluorination is that surface properties evolve under the simultaneous influence of fluorine-containing radicals, vacuum ultraviolet (VUV) radiation, and ion bombardment. ${ }^{[8]}$

A measure of the fluorination of a hydrocarbon polymer is the $\mathrm{F} / \mathrm{C}$ atomic ratio of the surface layers, as determined by X-ray photoelectron spectroscopy (XPS or ESCA). Corbin et al. showed that in an inductively coupled $\mathrm{Ar} / \mathrm{F}_{2}=95 / 5$ discharge at $50 \mathrm{~W}$ and 2 Torr, fluorination of polyethylene (PE) to a F/C of 1.8 (the maximum F/C is 2.0) was achievable in less than 1 min. ${ }^{[9]}$ Exposure to elemental fluorine gas resulted in a F/C of 0.2 over 3 min. Anand et al. performed XPS to probe the surface layer and depth of fluorination after treatment of $\mathrm{PE}$ in an inductively coupled $\mathrm{He} / \mathrm{F}_{2}=95 / 5$ plasma. ${ }^{[10]}$ For a $3 \mathrm{mTorr}$ discharge at $50 \mathrm{~W}$, the fluorination depth was about $4 \mathrm{~nm}$ with there being competition between ion-assisted etching and fluorination. The fluorination depth increased with increase in pressure or flow rates and the fluorinated surface was crosslinked. Hopkins and Badyal treated a variety of polymers [including PE, poly(propylene) (PP), polyisoprene, polystyrene, polycarbonate] in $150 \mathrm{mTorr}, 50 \mathrm{~W}$ inductively coupled $\mathrm{CF}_{4}$ plasmas. ${ }^{[11]}$ They concluded that hydrogen abstraction from the polymer by fluorine to form HF is the initiating step to plasma fluorination. This is thermodynamically favored since $\mathrm{C}-\mathrm{H}$ bond strengths are $3-4 \mathrm{eV}$ as compared with $5.9 \mathrm{eV}$ for $\mathrm{H}-\mathrm{F}$ and $5.0 \mathrm{eV}$ for $\mathrm{C}-\mathrm{F}$ bonds. They found that, compared with saturated polymers, unsaturated polymers are more susceptible to plasma fluorination. A reaction pathway comprising fluorine addition at $\mathrm{C}=\mathrm{C}$ double bonds was suggested.

Bond energies in hydrocarbon polymers are $3-4 \mathrm{eV}$ while ions can gain tens to hundreds of $\mathrm{eV}$ in traversing the plasma sheath at the polymer surface in a low-pressure plasma. These ions are capable of breaking bonds, sputtering and affecting surface composition through bond scission, and subsequent crosslinking. The sputtering yields of ions are functions of incident ion energy, polymer surface bonding energy, and mass difference between the ions and the atom or molecular fragments on the polymer backbone. Stelmashuk et al. and Biederman et al. performed radiofrequency (rf) magnetron sputtering of PP in Ar plasmas over pressures of 5-67 mTorr and powers of 25-100 W..$^{[12,13]}$
Ion bombardment and subsequent heating of the PP caused changes in the molecular structure of the target including melting and crosslinking. They found that sputtering preferentially lowered the proportion of $\mathrm{CH}_{3}$ groups in the $\mathrm{PP}$, transforming them into $\mathrm{CH}$ and $\mathrm{CH}_{2}$ groups, which promoted crosslinking. They also found that the rates of sputtering of PP and PE are less than one-third that for polytetrafluoroethylene (PTFE). This is likely a result of the more favorable mass ratio of the incident $\mathrm{Ar}$ ions to the $\mathrm{C}-\mathrm{F}$ bond in PTFE as compared with the $\mathrm{C}-\mathrm{H}$ bond in PE. Biederman modeled bombardment of PE by Ar ions using molecular dynamics and proposed that the ions cause chain scission, crosslinking, and carbonization of the target. ${ }^{[14]}$ The ejected species were dominated by atomic and molecular hydrogen, but also included large chain fragments containing up to $20 \mathrm{CH}_{2}$ units.

Vacuum ultraviolet (VUV) radiation is typically produced in low-pressure plasmas. In particular, in $\mathrm{Ar} / \mathrm{F}_{2}$ plasmas, excited states of $\mathrm{F}, \mathrm{F}_{2}$, and Ar produce radiation in the range of 95-157 nm. Impurities (e.g., $\mathrm{H}_{2} \mathrm{O}, \mathrm{O}_{2}$, and $\mathrm{CO}_{2}$ ) also emit in this region $(115-360 \mathrm{~nm})$. The $\mathrm{C}-\mathrm{C}$ or $\mathrm{C}-\mathrm{H}$ bonds of hydrocarbon polymers absorb radiation below $160 \mathrm{~nm}$ producing hemolytic bond scission and giving rise to either polymer ablation or to the formation of functional groups and reactive sites (e.g., double bonds and radicals). ${ }^{[15-20]}$ Corbin et al. investigated the enhancement of fluorination of PE under VUV irradiation originating from a $\mathrm{He} / \mathrm{F}_{2}$ discharge. ${ }^{[21]}$ The PE was immersed in a $\mathrm{He} / \mathrm{F}_{2}$ mixture and isolated from the plasma by a VUV-transmitting window. They found that radiation below $180 \mathrm{~nm}$ increased the rate of fluorination. Dorofeev and Skurat performed photolysis of PP in vacuum with $147 \mathrm{~nm}$ radiation from a Xe lamp and subsequent UV absorption spectroscopy on the irradiated sample. ${ }^{[22-24]}$ They found that PP photolysis at $147 \mathrm{~nm}$ primarily liberates $\mathrm{H}_{2}$ along with the formation of a $\mathrm{C}=\mathrm{C}$ bond with a quantum yield of about 0.25 . The scission of the $\mathrm{C}-\mathrm{C}$ bond produces two radicals that undergo disproportionation forming a methyl group and a chain-end double bond. They also observed scission of $\mathrm{C}-\mathrm{H}$ and $\mathrm{C}-\mathrm{C}$ bonds, which splits the atomic hydrogen and methyl groups, respectively, with a quantum yield about 0.025 .

Ono et al. studied VUV photo-degradation of PTFE by ultraviolet photoelectron spectroscopy (UPS) and quadruple mass spectrometry. ${ }^{[25]}$ They found that, unlike the photolysis of $\mathrm{PP}$ and $\mathrm{PE}, \mathrm{C}=\mathrm{C}$ bond generation is not a major process. They found $\mathrm{CF}_{n}(n=1-3)$ in the ejecta, indicating that the polymer $\mathrm{C}-\mathrm{C}$ backbone undergoes scission, a process also observed by Skurat and Nikiforov. ${ }^{[26]}$ Ono et al. estimated the quantum yield for atomic fluorine photolysis at $147 \mathrm{~nm}$ to be 0.0025 .

In this paper, we present results from a computational investigation of the gas-phase and surface kinetics during the fluorination of PP in a low-pressure capacitively coupled plasma (CCP) sustained in $\mathrm{Ar} / \mathrm{F}_{2}$ while accounting 
for both ion bombardment and VUV illumination. A surface reaction mechanism for the fluorination of PP films was developed, incorporated into a two-dimensional model for gas and surface processes, and applied to a CCP reactor patterned after an industrial prototype. ${ }^{[27]}$ We found that the degree of fluorination, as expressed by the $\mathrm{F} / \mathrm{C}$ ratio, affects the rate of additional fluorination due to a deactivation effect and steric hindrance by adjacent $\mathrm{F}$ atoms. For films electrically floating in the plasma (and not in contact with an electrode) and with moderate exposure times (<tens of seconds), ion bombardment is not particularly important to the final $\mathrm{F} / \mathrm{C}$ ratio. However, given longer exposure time or placement of the film on an electrode, ion sputtering produces significant changes in surface composition. In general, photon-induced reactions have little affect on film properties for moderate exposure times (<tens of seconds) largely due to the lower magnitudes of photon fluxes as compared with radical and ion fluxes. We found that fluorination generally increases monotonically with power, pressure, and $\mathrm{F}_{2}$ concentration. Good agreement for fluorination rates and surface compositions between model and experimental results was achieved.

The integrated surface kinetics model and plasmaequipment model used in this study and the gas-phase reaction mechanism are described in the Description of the Model and Gas Phase Reaction Mechanism section. The surface reaction mechanism is described in the Surface Reaction Mechanism for PP Fluorination section. Plasma properties for $\mathrm{Ar} / \mathrm{F}_{2}$ mixtures in the $\mathrm{CCP}$ reactor are discussed in the Plasma Properties of $\mathrm{Ar} / \mathrm{F}_{2}$ Plasma section. Results for plasma fluorination of PP are presented in the Plasma Fluorination of PP. Concluding remarks are found in the Conclusion section.

\section{Description of the Model and Gas Phase Reaction Mechanism}

The integrated plasma equipment-surface kinetics model used in this investigation has been previously described and so will be only briefly discussed here. ${ }^{[28]}$ The Hybrid Plasma Equipment Model (HPEM) is a 2-dimensional fluid hydrodynamics simulation that, for $\mathrm{CCP}$ reactors, employs five modules: the Electron Energy Transport Module (EETM), the Fluid Kinetics Module (FKM), the Plasma Chemistry Monte Carlo Module (PCMCM), the Surface Kinetics Module (SKM), and the Monte Carlo Radiation Transport Module (MCRTM). Using a Monte Carlo simulation (MCS) for secondary electrons emitted from surfaces, the EETM solves for electron-impact source functions and transport coefficients based on phase-resolved electrostatic fields from the FKM. Results from the EETM are passed to the FKM, which solves continuity, momentum, and energy equations for neutrals and ions, the continuity equation for electrons, and Poisson's equation to determine time-resolved electrostatic fields. In this particular implementation, the electron energy equation for bulk electron energy transport is solved within the FKM. Source functions and densities of ions and excited states are then used in the PCMCM, SKM, and MCRTM to update gas-phase rate coefficients and surface coverages. The outputs from the FKM are then fed back to the EETM, a sequence that constitutes an iteration. Additional iterations are computed until a cycle-averaged steady state is achieved. Acceleration techniques are used to speed the cycle-averaged convergence of plasma properties.

Following every iteration, the electric fields and source functions for ions are recorded as a function of position and phase in the rf cycle. With these values, the energy and angular distributions of ions (IEADs) incident on the PP film are obtained using the PCMCM described in detail in the ref. ${ }^{[29]}$ The IEADs are used to compute probabilities of energy-dependent surface processes such as sputtering. The MCRTM, described in the ref., ${ }^{[30]}$ is also called after every iteration to provide photon fluxes incident on the PP film. The VUV radiation tracked in the model originates from resonance transitions from $\mathrm{F}(3 \mathrm{~s})$ and $\operatorname{Ar}(4 \mathrm{~s})$ and from $\mathrm{F}_{2}\left(\mathrm{C}^{1} \sum_{u}, \mathrm{H}^{1} \Pi_{u}\right)$. An outcome of the MCRTM is trapping factors for resonance radiation and these factors are used to update the radiative lifetimes of the radiating states in the reaction mechanism.

With the surface reaction mechanism described in the Surface Reaction Mechanism for PP Fluorination section, the SKM is called after each iteration to integrate the coupled rate equations for the coverage of surface species using site-balance techniques. Input to the SKM includes fluxes of electrons, ions (and energy distributions), neutrals, and VUV radiation from the other modules of the HPEM. The SKM is described in detail in the ref. ${ }^{[31]}$

A schematic of the CCP reactor used in this study is shown in Figure $1 .^{[27]}$ The parallel-plate reactor has electrodes $46 \mathrm{~cm} \times 46 \mathrm{~cm}$ separated by $2.54 \mathrm{~cm}$. One electrode is grounded and the opposite is powered at $10 \mathrm{MHz}$ through a blocking capacitor. The feedstock gases are injected

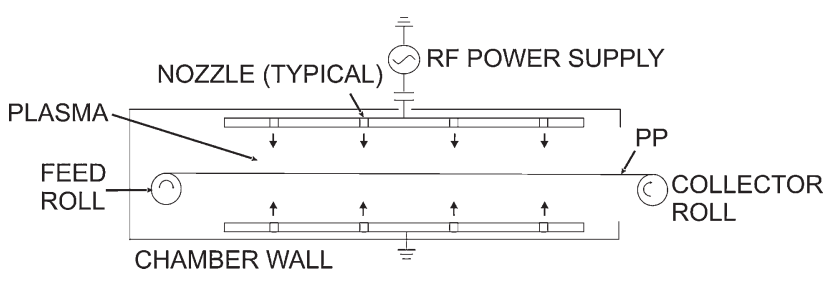

Figure 1. Schematic of the plasma fluorination reactor. The plasma is produced in a capacitively coupled discharge between two parallel electrodes. The PP web traverses the plasma region at speeds of a few to tens of $\mathrm{cm} \cdot \mathrm{s}^{-1}$ with residence times of a few to tens of seconds. 
through nozzles in both electrodes and pumped out at the right side of the reactor. The reactor is integrated into a web-processing line where a polymer film enters from the left side of the reactor and translates to the right where, in an actual device, the collector roll might be located. Typical web speeds are up to several to tens of $\mathrm{cm} \cdot \mathrm{s}^{-1}$ and the film spends from seconds to tens of seconds in the discharge. The thickness of the PP film is $2.5 \times 10^{-3} \mathrm{~cm}$, which is smaller than our mesh resolution. In principle, this discrepancy should only affect the electrical properties of the film. Accordingly, the permittivity (dielectric constant) of the film was scaled so that the area capacitance $\left(\mathrm{F} \cdot \mathrm{cm}^{-2}\right)$ is the same as the actual film. The model is two-dimensional, and so only the plane perpendicular to the film and parallel to the web direction is resolved.

The movement of the polymer film through the plasma was also modeled. The speed and direction of the web are specified. Assuming that the film is moving from left-toright as shown in Figure 1, during execution of the SKM, at every $\Delta t=\Delta x / v(\Delta x$ is the numerical mesh spacing of the polymer film and $v$ is the web speed), the surface properties of the mesh point to the left on the surface are translated to the mesh point to the right. The surface properties of the leftmost film mesh point are set to the initial conditions (untreated PP in this case) whereas the surface properties of the rightmost mesh point are translated outside the computational domain. These latter surface compositions are referred to as the exit properties of the film.

The gas-phase reaction mechanism for $\mathrm{Ar} / \mathrm{F}_{2}$ plasma is summarized in Table 1 . With mole fractions of $F_{2}$ greater than a few percent, the production of $\mathrm{F}$ atoms mainly comes from electron dissociative attachment of $\mathrm{F}_{2}$, producing highly electronegative plasmas. Direct dissociation of $\mathrm{F}_{2}$, due to excitation to the dissociative electronic states $\mathrm{F}_{2}\left(a^{3} \Pi\right)$ and $\mathrm{F}_{2}\left(A^{1} \Pi\right)$ (minimum threshold energy $3.16 \mathrm{eV}$ ), is not a major contributor at our conditions in comparison with dissociative attachment. The density of $\mathrm{F}$ atoms is generally five orders of magnitude larger than that of $\mathrm{F}^{+}$for our conditions. Therefore, the majority of loss of $\mathrm{F}^{-}$results from associative detachment between $\mathrm{F}^{-}$and $\mathrm{F}$ as opposed to ion-ion neutralization processes. The gas phase reaction mechanism includes $\mathrm{Ar}(4 \mathrm{~s})$ metastable $\left(\mathrm{Ar}^{*}\right.$ in Table 1), radiative states of $\operatorname{Ar}(4 s)\left(\mathrm{Ar}^{* * *}\right.$ in Table 1$)$, and $\operatorname{Ar}(4 \mathrm{p})$ radiative states $\left(\mathrm{Ar}^{* *}\right.$ in Table 1$)$. Resolving these states in the reaction mechanism is necessary to characterize the photon transport in $\mathrm{Ar} / \mathrm{F}_{2}$ plasmas.

\section{Surface Reaction Mechanism for PP Fluorination}

Isotactic PP is a saturated hydrocarbon polymer with a carbon backbone containing hydrogen and methyl $\left(-\mathrm{CH}_{3}\right)$ groups arranged in an alternating fashion (see Figure 2). The reactivities of the hydrogen atoms in $\mathrm{PP}$ depend on the position of the $\mathrm{C}$ atom to which they are attached: primary $C$ atoms $\left(C_{P}\right)$ are bonded to one other carbon atom, secondary $C$ atoms $\left(C_{S}\right)$ are bonded to two other $C$ atoms, and tertiary $C$ atoms $\left(C_{T}\right)$ are bonded to three other $C$ atoms. Therefore, a PP repeating unit consists of two secondary $\mathrm{H}$ atoms $\left(\mathrm{H}_{\mathrm{S}}\right)$, a tertiary $\mathrm{H}$ atom $\left(\mathrm{H}_{\mathrm{T}}\right)$, and three primary $\mathrm{H}$ atoms $\left(\mathrm{H}_{\mathrm{P}}\right)$ in the methyl $\left(-\mathrm{CH}_{3}\right)$ group. The reactivities of $\mathrm{H}$ atoms bound to $\mathrm{C}$ atoms generally scale as $\mathrm{H}_{\mathrm{T}}>\mathrm{H}_{\mathrm{S}}>\mathrm{H}_{\mathrm{P}}$.

The general surface reaction mechanism for PP fluorination is given in Table 2 . The initial total density of surface sites, as reported for virgin $\mathrm{PP}$, is $\approx 10^{15} \mathrm{~cm}^{-2}$. ${ }^{32]}$ The total number of surface sites may vary with treatment time as, for example, methyl groups are removed from the PP chain by ions or photons, or gaps are made in the PP chain by ion bombardment. When a gap is made in the PP chain, reactions occur with the newly formed free radicals in the broken chain as well as with the exposed PP chain in the underlying layer.

The basic fluorination process is represented by the sequence of reactions of abstraction and passivation;

$$
\begin{aligned}
& -\left(\mathrm{CH}_{2}\right)(\mathrm{CH})\left(\mathrm{CH}_{3}\right)-+{ }^{\cdot} \mathrm{F}_{g} \\
& \rightarrow-\left(\mathrm{CH}_{2}\right)(\mathrm{CH})\left(\mathrm{CH}_{2}^{-}\right)-+\mathrm{HF}_{g} \\
& -\left(\mathrm{CH}_{2}\right)(\mathrm{CH})\left(\mathrm{CH}_{2}^{\cdot}\right)-+{ }^{\cdot} \mathrm{F}_{g} \\
& \rightarrow-\left(\mathrm{CH}_{2}\right)(\mathrm{CH})\left(\mathrm{CH}_{2} \mathrm{~F}\right)- \\
& -\left(\mathrm{CH}_{2}\right)(\mathrm{CH})(\mathrm{CH})-+\mathrm{F}_{2 g} \\
& \rightarrow-\left(\mathrm{CH}_{2}\right)(\mathrm{CH})\left(\mathrm{CH}_{2} \mathrm{~F}\right)-+\mathrm{F}_{g}
\end{aligned}
$$

The subscript $g$ denotes a gas phase species. $-\left(\mathrm{CH}_{2}\right)(\mathrm{CH})\left(\mathrm{CH}_{3}\right)$ - is the repeating unit of the saturated hydrocarbon, represented here as having a linear arrangement of $\mathrm{C}_{\mathrm{S}}, \mathrm{C}_{\mathrm{T}}$, and $\mathrm{C}_{\mathrm{P}}$. As such, $-\left(\mathrm{CH}_{2}\right)(\mathrm{CH})\left(\mathrm{CH}_{2}\right)_{-}$ represents a polymer free radical on the $C_{P}$. $-\left(\mathrm{CH}_{2}\right)(\mathrm{CH})\left(\mathrm{CH}_{2} \mathrm{~F}\right)-$ represents a fluorinated site on the $C_{P}$. In this sequence, a $\mathrm{F}$ atom extracts a $\mathrm{H}$ atom from the $P P$ chain at the $C_{P}$ site to form gas phase $H F$ and an alkyl site (e.g., a free radical on a carbon atom). That radical is then passivated by either a $\mathrm{F}$ atom to form $\mathrm{C}-\mathrm{F}$ surface bonding, or a $\mathrm{F}$ atom is abstracted from a gas-phase $\mathrm{F}_{2}$ to form the C-F. For clarity, a specific reaction sequence has been shown for the $C_{P}$ site. The modeled reaction mechanism contains all possible combinations and permutations of 
Table 1. Ar/ $\mathrm{F}_{2}$ gas-phase reaction mechanism.

\section{Species}

\begin{tabular}{|c|c|c|}
\hline $\mathbf{F}_{2} \mathbf{F}_{2}^{*}\left(\mathbf{C}^{1} \sum_{\mathbf{u}}, \mathbf{H}^{1} \Pi_{\mathbf{u}}\right) \mathbf{F}_{2}^{+}$ & $\mathbf{F ~ F}(3 s) \mathrm{F}^{+} \mathrm{F}^{-}$ & $\operatorname{Ar} \operatorname{Ar}^{*}\left(4 s-{ }^{3} \mathrm{P}_{0},{ }^{3} \mathrm{P}_{2}\right) \operatorname{Ar}{ }^{* *}(4 \mathrm{p}) \mathrm{Ar}^{* * *}\left(4 \mathrm{~s}-{ }^{3} \mathrm{P}_{1},{ }^{1} \mathrm{P}_{1}\right) \mathrm{E}$ \\
\hline Reaction $^{\text {a) }}$ & Rate coefficient $t^{\text {b) }}$ & Reference \\
\hline \multicolumn{3}{|l|}{ Electron impact } \\
\hline $\mathrm{e}+\mathrm{F}_{2} \rightarrow \mathrm{F}+\mathrm{F}+\mathrm{e}$ & c) & [46] \\
\hline $\mathrm{e}+\mathrm{F}_{2} \rightarrow \mathrm{F}^{-}+\mathrm{F}$ & c) & [46] \\
\hline $\mathrm{e}+\mathrm{F}_{2} \rightarrow F_{2}^{*}+\mathrm{e}$ & c) & [46] \\
\hline $\mathrm{e}+\mathrm{F}_{2} \rightarrow \mathrm{F}_{2}^{+}+\mathrm{e}+\mathrm{e}$ & c) & [46] \\
\hline $\mathrm{e}+\mathrm{F}_{2}^{+} \rightarrow \mathrm{F}+\mathrm{F}$ & $8 \times 10^{-8} T_{e}^{-0.5}$ & [46] \\
\hline $\mathrm{e}+\mathrm{F} \rightarrow \mathrm{F}^{*}+\mathrm{e}$ & c) & [47] \\
\hline $\mathrm{e}+\mathrm{F}^{*} \rightarrow \mathrm{F}+\mathrm{e}$ & c) & [47] \\
\hline $\mathrm{e}+\mathrm{F}^{*} \rightarrow \mathrm{F}^{+}+\mathrm{e}$ & c) & [47] \\
\hline $\mathrm{F}^{*} \rightarrow \mathrm{F}$ & $5 \times 10^{7} \mathrm{~s}^{-1}$ & d) \\
\hline $\mathrm{e}+\mathrm{F} \rightarrow \mathrm{F}^{+}+\mathrm{e}+\mathrm{e}$ & c) & [47] \\
\hline $\mathrm{e}+\mathrm{Ar} \rightarrow \mathrm{Ar}^{*}+\mathrm{e}$ & c) & [48] \\
\hline $\mathrm{e}+\mathrm{Ar} \rightarrow \mathrm{Ar}^{* *}+\mathrm{e}$ & c) & [48] \\
\hline $\mathrm{e}+\mathrm{Ar} \rightarrow \mathrm{Ar}^{+}+\mathrm{e}+\mathrm{e}$ & c) & [49] \\
\hline $\mathrm{e}+\mathrm{Ar}^{*} \rightarrow \mathrm{Ar}^{+}+\mathrm{e}+\mathrm{e}$ & c) & [50] \\
\hline $\mathrm{e}+\mathrm{Ar}^{*} \rightarrow \mathrm{Ar}+\mathrm{e}$ & c) & {$[48]^{\text {e) }}$} \\
\hline $\mathrm{e}+\mathrm{Ar}^{*} \rightarrow \mathrm{Ar}^{* *}+\mathrm{e}$ & c) & [51] \\
\hline $\mathrm{e}+\mathrm{Ar}^{* *} \rightarrow \mathrm{Ar}^{+}+\mathrm{e}+\mathrm{e}$ & c) & {$[52]$} \\
\hline $\mathrm{e}+\mathrm{Ar}^{* *} \rightarrow \mathrm{Ar}+\mathrm{e}$ & c) & {$[48]^{e)}$} \\
\hline $\mathrm{e}+\mathrm{Ar}^{* *} \rightarrow \mathrm{Ar}^{*}+\mathrm{e}$ & c) & {$[51]^{\text {e) }}$} \\
\hline $\mathrm{Ar}^{* *} \rightarrow \mathrm{Ar}^{*}$ & $1 \times 10^{5} \mathrm{~s}^{-1}$ & d) \\
\hline $\mathrm{e}+\mathrm{Ar}^{*} \rightarrow \mathrm{Ar}^{* * *}+\mathrm{e}$ & $10^{-8} \exp \left(-0.075 / T_{\mathrm{e}}\right)$ & f)g) \\
\hline $\mathrm{e}+\mathrm{Ar}^{* * *} \rightarrow \mathrm{Ar}^{*}+\mathrm{e}$ & $1 \times 10^{-8}$ & f) \\
\hline $\mathrm{e}+\mathrm{Ar}^{* *} \rightarrow \mathrm{Ar}^{* * *}+\mathrm{e}$ & $8.87 \times 10^{-7} T_{\mathrm{e}}^{0.5}$ & f)g) \\
\hline $\mathrm{e}+\mathrm{Ar}^{* * *} \rightarrow \mathrm{Ar}^{* *}+\mathrm{e}$ & $8.87 \times 10^{-7} T_{\mathrm{e}}^{0.5} \exp \left(-1.52 / T_{\mathrm{e}}\right)$ & f)g) \\
\hline $\mathrm{e}+\mathrm{Ar}^{* * *} \rightarrow \mathrm{Ar}^{+}+\mathrm{e}+\mathrm{e}$ & $10^{-7} T_{\mathrm{e}}^{0.6} \exp \left(-3.8 / T_{\mathrm{e}}\right)$ & f)g) \\
\hline \multicolumn{3}{|l|}{ Radiative transitions } \\
\hline$\overline{F_{2}^{*} \rightarrow F_{2}}$ & $2 \times 10^{8} \mathrm{~s}^{-1}$ & {$[53]^{\mathrm{d})}$} \\
\hline $\mathrm{F}^{*} \rightarrow \mathrm{F}$ & $5 \times 10^{7} \mathrm{~s}^{-1}$ & {$[54]^{\text {d) }}$} \\
\hline $\mathrm{Ar}^{* * *} \rightarrow \mathrm{Ar}$ & $1 \times 10^{8} \mathrm{~s}^{-1}$ & {$[55]^{d)}$} \\
\hline \multicolumn{3}{|l|}{ Heavy particle reactions } \\
\hline $\mathrm{Ar}^{*}+\mathrm{Ar}^{*} \rightarrow \mathrm{Ar}^{+}+\mathrm{Ar}+\mathrm{e}$ & $1.2 \times 10^{-9}$ & [56] \\
\hline $\mathrm{Ar}^{* *}+\mathrm{Ar}^{* *} \rightarrow \mathrm{Ar}^{+}+\mathrm{Ar}+\mathrm{e}$ & $1.2 \times 10^{-9}$ & [56] \\
\hline $\mathrm{Ar}^{*}+\mathrm{Ar}^{* *} \rightarrow \mathrm{Ar}^{+}+\mathrm{Ar}+\mathrm{e}$ & $1.2 \times 10^{-9}$ & [57] \\
\hline $\mathrm{Ar}^{*}+\mathrm{Ar}^{* * *} \rightarrow \mathrm{Ar}^{+}+\mathrm{Ar}+\mathrm{e}$ & $1.2 \times 10^{-9}$ & {$[56]$} \\
\hline $\mathrm{Ar}^{* *}+\mathrm{Ar}^{* * *} \rightarrow \mathrm{Ar}^{+}+\mathrm{Ar}+\mathrm{e}$ & $1.2 \times 10^{-9}$ & [56] \\
\hline $\mathrm{Ar}^{* * *}+\mathrm{Ar}^{* * *} \rightarrow \mathrm{Ar}^{+}+\mathrm{Ar}+\mathrm{e}$ & $1.2 \times 10^{-9}$ & [56] \\
\hline $\mathrm{Ar}^{*}+\mathrm{Ar} \rightarrow \mathrm{Ar}^{* * *}+\mathrm{Ar}+\mathrm{e}$ & $10^{-10} T_{g}^{0.5} \exp \left(-875 / T_{g}\right)$ & {$[56]^{\text {h) }}$} \\
\hline $\mathrm{Ar}^{* * *}+\mathrm{Ar} \rightarrow \mathrm{Ar}^{*}+\mathrm{Ar}+\mathrm{e}$ & $1 \times 10^{-10}$ & [56] \\
\hline
\end{tabular}


Table 1. Continued

\begin{tabular}{lcc}
\hline Reaction $^{\text {a) }}$ & Rate coefficient $^{\text {b) }}$ & Reference \\
\hline $\mathrm{Ar}^{+}+\mathrm{Ar} \rightarrow \mathrm{Ar}^{+}+\mathrm{Ar}$ & $5.7 \times 10^{-10}$ & {$[57]$} \\
$\mathrm{Ar}^{+}+\mathrm{F}_{2} \rightarrow F_{2}^{+}+\mathrm{Ar}$ & $1 \times 10^{-11}$ & $\mathrm{f})$ \\
$\mathrm{F}^{+}+\mathrm{F} \rightarrow \mathrm{F}^{+}+\mathrm{F}$ & $1 \times 10^{-9}$ & {$[58]$} \\
$F_{2}^{+}+\mathrm{F}_{2} \rightarrow \mathrm{F}_{2}^{+}+\mathrm{F}_{2}$ & $1 \times 10^{-9}$ & $\mathrm{f})$ \\
$F_{2}^{+}+\mathrm{F} \rightarrow \mathrm{F}^{+}+\mathrm{F}_{2}$ & $7.9 \times 10^{-10}$ & {$[58]$} \\
$\mathrm{F}^{-}+\mathrm{Ar}^{+} \rightarrow \mathrm{F}+\mathrm{Ar}$ & $5 \times 10^{-7}$ & {$[59]$} \\
$\mathrm{F}^{-}+\mathrm{F}_{2}^{+} \rightarrow \mathrm{F}_{2}+\mathrm{F}$ & $1 \times 10^{-7}$ & {$[58]$} \\
$\mathrm{F}^{-}+\mathrm{F}^{+} \rightarrow \mathrm{F}+\mathrm{F}$ & $7 \times 10^{-7}$ & {$[58]$} \\
$\mathrm{F}^{-}+\mathrm{F} \rightarrow \mathrm{F}_{2}+\mathrm{e}$ & $1 \times 10^{-10}$ & {$[60]$} \\
$\mathrm{F}+\mathrm{F}+\mathrm{M} \rightarrow \mathrm{F}_{2}+\mathrm{M}$ & $6.8 \times 10^{-34} \mathrm{~cm}^{6} \cdot \mathrm{s}^{-1}$ & {$[61]$}
\end{tabular}

a) Only reactions directly affecting species densities are shown here. Additional electron impact collisions (e.g., momentum transfer, vibrational excitation) are included in the solution of Boltzmann's equation; ${ }^{\text {b) }}$ rate coefficients have units of $\mathrm{cm}^{3} \cdot \mathrm{s}^{-1}$ unless noted otherwise; ${ }^{c}$ rate coefficient is calculated from the electron energy distribution obtained in the EETM using the cross-section from the cited reference; ${ }^{d)}$ natural lifetime. Lifetime used in the model is the trapped value obtained from the MCRTM; ${ }^{\text {e) }}$ cross-section was obtained by detailed balance; ${ }^{\mathrm{f}}$ estimated; ${ }^{\mathrm{g})} T_{\mathrm{e}}$ is the electron temperature $(\mathrm{eV}) ;{ }^{\mathrm{h})} T_{\mathrm{g}}$ is the gas temperature (K).

$$
\begin{aligned}
& \text { a) } \quad\left[\begin{array}{cc}
\mathrm{H} & \mathrm{CH}_{3} \\
\mathrm{IS} & \mathrm{IP} \\
-\mathrm{C} & \mathrm{C}- \\
\mathrm{I} & \mathrm{IT} \\
\mathrm{H} & \mathrm{H}
\end{array}\right] \\
& \left.\{\}^{H F}\right\}^{F_{2}} \\
& \text { hv } \\
& \begin{array}{rr}
\mathrm{H} & \mathrm{CHF} \\
\mathrm{I} & \mathrm{I} \\
-\mathrm{C} & -\mathrm{C}-\mathrm{F} \\
\mathrm{I} & \mathrm{I} \\
\mathrm{F} & \mathrm{H}
\end{array} \\
& \begin{array}{cc}
\mathrm{H} \\
\mathrm{I} \\
\mathrm{C} \\
\mathrm{I}
\end{array} \\
& \mathrm{CH}_{3} \mathrm{H}
\end{aligned}
$$

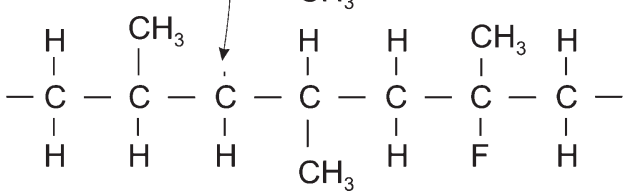

Figure 2. Schematic of surface reaction mechanism. (a) A repeating unit of PP. The $\mathrm{P}, \mathrm{S}$, and T subscripts denote the primary, secondary, and tertiary carbon sites. (b) Surface site balance model. PP is a saturated hydrocarbon polymer consisting of two secondary $\mathrm{H}$ atoms, a tertiary $\mathrm{H}$ atom, and a methyl group containing 3 primary $\mathrm{H}$ atoms attached to the carbon backbone. The total number of surface sites is allowed to vary in the model as groups are sputtered. $\mathrm{I}^{+}$represents ions and $h v$ represents photons. $\mathrm{CH}_{n} \mathrm{~F}_{m}$ denotes fragments of the PP backbone that are ablated by ions or photons. partially and fully fluorinated PP sites. For example,

$$
\begin{aligned}
& -(\mathrm{CHF})(\mathrm{CH})\left(\mathrm{CH}_{2} \mathrm{~F}\right)-+\mathrm{F}_{g} \\
& -\rightarrow-(\mathrm{CF})(\mathrm{CH})\left(\mathrm{CH}_{2} \mathrm{~F}\right)-+\mathrm{HF}_{g}
\end{aligned}
$$

$$
\begin{gathered}
-(\mathrm{CF})(\mathrm{CH})\left(\mathrm{CH}_{2} \mathrm{~F}\right)-+\mathrm{F}_{\mathrm{g}} \\
\rightarrow-\left(\mathrm{CF}_{2}\right)(\mathrm{CH})\left(\mathrm{CH}_{2} \mathrm{~F}\right)
\end{gathered}
$$

represent the abstraction of $\mathrm{H}$ from a partially fluorinated $C_{S}$ site and the subsequent passivation to form a fully fluorinated $C_{S}$. As discussed below, the probability of abstraction and fluorination depends on the location on the PP chain (e.g., primary, secondary, or tertiary) and the state of local fluorination (e.g., is there a fluorinated site adjacent to the $\mathrm{H}$ atom to be abstracted). The latter dependence results from both steric factors (i.e., physical blocking) from the larger $\mathrm{F}$ atoms and deactivation effects. To account for all permutations of abstraction and fluorination from all combinations of partially fluorinated sites, alkyl sites, and chain fragments, the mechanism has 4540 reactions. The successive reactions of $\mathrm{H}$ abstraction, followed by passivation by $\mathrm{F}$ or $\mathrm{F}_{2}$ progresses until, ideally, all $\mathrm{H}$ atoms are replaced by $\mathrm{F}$ atoms. For PP, this would result in a $\mathrm{F} / \mathrm{C}=2$. 
Table 2. Surface reaction mechanism for $\mathrm{PP}$ in $\mathrm{Ar} / \mathrm{F}_{2}$ plasmas.

\section{Reaction $^{\text {a) }}$}

Probability

Comment

\section{$\mathrm{H}$ abstraction and $\mathrm{F}$ addition}

(1)

(2)

(3)

Crosslinking

(4)

Ion sputtering of $C_{S}$

(5)

$$
\begin{aligned}
& -\left(\mathrm{CH}_{2}\right)(\mathrm{CH})\left(\mathrm{CH}_{3}\right)-+\mathrm{F}_{g} \rightarrow-\left(\mathrm{CH}_{2}\right)(\mathrm{CH})\left(\mathrm{CH}_{2}^{-}\right)-+\mathrm{HF}_{\mathrm{g}} \\
& -\left(\mathrm{CH}_{2}\right)\left(\mathrm{C}^{\cdot}\right)\left(\mathrm{CH}_{3}\right)-+\mathrm{F}_{\mathrm{g}} \rightarrow-\left(\mathrm{CH}_{2}\right)(\mathrm{CF})\left(\mathrm{CH}_{3}\right)- \\
& -\left(\mathrm{CH}_{2}\right)\left(\mathrm{C}^{\cdot}\right)\left(\mathrm{CH}_{3}\right)-+\mathrm{F}_{2 g} \rightarrow-\left(\mathrm{CH}_{2}\right)(\mathrm{CF})\left(\mathrm{CH}_{3}\right)-+\mathrm{F}_{g}
\end{aligned}
$$

Table 3

Table 4

Table 4

$$
-\left(\mathrm{CH}_{2}\right)(\mathrm{CH})\left(\mathrm{CH}_{2}^{-}\right)-+\mathrm{M} \rightarrow-\left(\mathrm{CH}_{2}\right)(\mathrm{CH})\left(\mathrm{CRH}_{2}\right)-
$$

Table 5

$$
-\mathrm{PP}-\left(\mathrm{CH}_{2}\right)(\mathrm{CH})\left(\mathrm{CH}_{3}\right)-\mathrm{PP}-+\mathrm{I}_{g}^{+} \rightarrow-\mathrm{PP} \cdot+\cdot(\mathrm{CH})\left(\mathrm{CH}_{3}\right)-\mathrm{PP}-+{ }^{\cdot} \mathrm{CH}_{2 g}+\mathrm{I}_{g}
$$

Table 5

Table 5

$$
-\mathrm{PP}-\left(\mathrm{CH}_{2}\right)(\mathrm{CH})\left(\mathrm{CH}_{3}\right)-\mathrm{PP}-+\mathrm{I}_{g}^{+} \rightarrow-\mathrm{PP}+{ }^{\cdot}\left(\mathrm{CH}_{2}\right)-\mathrm{PP}-+{ }^{\cdot} \mathrm{CH}\left(\mathrm{CH}_{3}\right)_{g}+\mathrm{I}_{g}
$$

Table 5

$$
-\mathrm{PP}-\left(\mathrm{CH}_{2}\right)(\mathrm{CH})\left(\mathrm{CH}_{3}\right)-\mathrm{PP}-+\mathrm{I}_{g}^{+} \rightarrow-\mathrm{PP}-\left(\mathrm{CH}_{2}\right)(\mathrm{CH} \cdot)-\mathrm{PP}-+\mathrm{CH}_{3 g}+\mathrm{I}_{g}
$$

Table 5

$$
-\mathrm{PP}-\mathrm{PP}-\mathrm{PP}-+\mathrm{I}_{g}^{+} \rightarrow-\mathrm{PP} \cdot+\cdot \mathrm{PP}-+{ }^{\cdot} \mathrm{PP}_{g}+\mathrm{I}_{g}
$$

Table 6

Photon $\mathrm{C}-\mathrm{C}$ bond scission and disproportionation

Photon ablation of $C_{P}$

$$
\begin{aligned}
& -\mathrm{PP}-(\mathrm{CHF})(\mathrm{CH})\left(\mathrm{CH}_{2} \mathrm{~F}\right)-\mathrm{PP}-+h v \rightarrow-\mathrm{PP}-(\mathrm{CHF})\left(\mathrm{CH}_{2}\right)\left(\mathrm{CH}_{2} \mathrm{~F}\right)+\cdot \mathrm{PP}- \\
& -\mathrm{PP}-(\mathrm{CHF})(\mathrm{CH})\left(\mathrm{CH}_{2} \mathrm{~F}\right)-\mathrm{PP}-+h v \rightarrow-\mathrm{PP} \cdot+(\mathrm{CHF})=(\mathrm{C})\left(\mathrm{CH}_{2} \mathrm{~F}\right)-\mathrm{PP}-
\end{aligned}
$$

Table 6

Table 6 e) Saturation of double bonds by $\mathrm{F}$

$$
-(\mathrm{CF})=(\mathrm{C})\left(\mathrm{CH}_{2} \mathrm{~F}\right)-+\mathrm{F}_{g} \rightarrow-(\mathrm{CF})(\mathrm{CF})\left(\mathrm{CH}_{2} \mathrm{~F}\right)-
$$

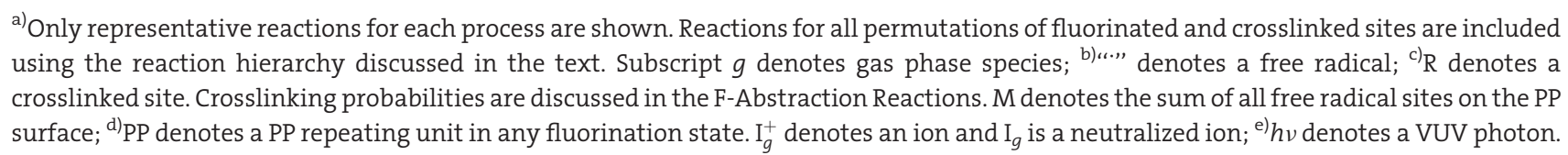

In general, surface reactions with plasma-delivered species can be classified as: fluorine abstraction of hydrogen, fluorine addition, ion sputtering, and photon induced. With the exception of fluorine addition, these reactions create free radical sites, thereby introducing the probability of crosslinking, that is the formation of a $\mathrm{C}-\mathrm{C}$ bond between different PP molecules or between different portions of the same PP molecule. As any functional group can further react with neutrals, ions, or photons, many dozens of different configurations of the PP backbone can be produced. To adequately characterize such a complex mechanism using a reasonable number of parameters, we implemented a reaction hierarchy that addresses the major pathways in a systematic way while also accounting for secondary pathways.

\section{F-Abstraction Reactions}

The fluorination process starts with the abstraction of $\mathrm{H}$ from the PP backbone creating alkyl sites for subsequent fluorination. $\mathrm{H}$ can be abstracted from any of the primary, secondary or tertiary sites in PP. The probability of abstraction generally scales as $\mathrm{H}_{\mathrm{T}}>\mathrm{H}_{\mathrm{S}}>\mathrm{H}_{\mathrm{P}}$. For example, the reactivity for abstraction of $\mathrm{H}$ from $\mathrm{PP}$ by $\mathrm{O}$ atoms, scales

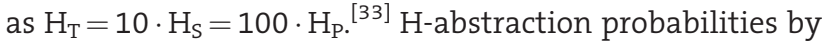
$\mathrm{F}$ atoms should be greater than those by $\mathrm{O}$ atoms due to the 
larger electron affinity of $\mathrm{F}$ atoms. To calibrate these probabilities, analogies were made to gas-phase reactions. One example is the abstraction of $\mathrm{H}$ by $\mathrm{F}$ from isobutane,

$$
\begin{aligned}
& \text { iso }-\mathrm{C}_{4} \mathrm{H}_{10}+\mathrm{F} \rightarrow \text { iso }-\mathrm{C}_{4} \mathrm{H}_{9}+\mathrm{HF} \\
& \qquad \begin{array}{l}
k \\
=6.8 \times 10^{-11} \mathrm{~cm}^{3} \mathrm{~s}^{-1},{ }^{[34]}
\end{array} \\
& \text { iso }-\mathrm{C}_{4} \mathrm{H}_{10}+\mathrm{F} \rightarrow \text { tert }-\mathrm{C}_{4} \mathrm{H} \dot{9}+\mathrm{HF} \\
& \quad k=9.6 \times 10^{-11} \mathrm{~cm}^{3} \mathrm{~s}^{-1[34]}
\end{aligned}
$$

where $k$ is the room temperature rate coefficient. From these reactions, we estimated that the rate of $\mathrm{H}_{\mathrm{T}}$ abstraction is about 1.4 times larger than that of $\mathrm{H}_{\mathrm{p}}$. For this work, we used probabilities that scale as $\mathrm{H}_{T}=\mathrm{H}_{\mathrm{S}}=1.5 \cdot \mathrm{H}_{\mathrm{P}}$. To determine absolute surface reaction probabilities, we compared $\mathrm{H}$ abstraction by $\mathrm{F}$ atoms to $\mathrm{H}$ abstraction by $\mathrm{O}$ atoms in the gas phase,

$$
\begin{gathered}
\text { iso }-\mathrm{C}_{4} \mathrm{H}_{10}+\mathrm{O} \rightarrow \text { tert }-\mathrm{C}_{4} \mathrm{H}_{9}+\mathrm{OH} \\
k=3.0 \times 10^{-13} \mathrm{~cm}^{3} \mathrm{~s}^{-1[33]}
\end{gathered}
$$

The rate of $\mathrm{H}_{\mathrm{T}}$ abstraction by $\mathrm{O}$ atoms is about 100 times slower than by $\mathrm{F}$ atoms. With the probability for $\mathrm{H}_{\mathrm{T}}$ abstraction being $10^{-3}$ for $\mathrm{O}$ atoms, we assigned the reaction probability for abstraction by $\mathrm{F}$ atoms to be on the order of $10^{-1}$ [33]

This initial estimate for $\mathrm{H}$ abstraction by $\mathrm{F}$ atoms is for the fully hydrogenated PP site. It is known that H-atom abstraction and fluorination become progressively more difficult as F atoms are added to the PP backbone because of a deactivation effect and steric hindrance by those $\mathrm{F}$ atoms. ${ }^{[9,34]}$ To reduce the number of adjustable probabilities in the surface reaction mechanism to account for these dependencies, a hierarchy of reaction probabilities was developed based on the following considerations. Reaction probabilities will first depend on the reactivity of primary, secondary, and tertiary sites. Second, reactivities will depend on the local F/C ratio, thereby accounting for steric factors and electrophilic effects. To enable setting of relative rates of reactions of different fluorination states, reference was made to reactions of gas-phase analogs. For example, the rate of $\mathrm{H}$ atom abstraction by $\mathrm{F}$ from a long-chain alkane differs depending on the number of fluorinated bonds,

$$
\begin{gathered}
\mathrm{C}_{3} \mathrm{H}_{8}+\cdot \mathrm{F} \rightarrow \mathrm{n}-\mathrm{C}_{3} \mathrm{H}_{7}+\mathrm{HF} \\
k=5.8 \times 10^{-11} \mathrm{~cm}^{3} \mathrm{~s}^{-1[35]}
\end{gathered}
$$

$$
\begin{gathered}
\mathrm{C}_{2} \mathrm{~F}_{5} \mathrm{CF}_{2} \mathrm{H}+\mathrm{F} \rightarrow n-\mathrm{C}_{3} \mathrm{~F}_{7}+\mathrm{HF} \\
k=3.2 \times 10^{-13} \mathrm{~cm}^{3} \mathrm{~s}^{-1[36]}
\end{gathered}
$$

The rate of abstraction for $\mathrm{C}_{2} \mathrm{~F}_{5} \mathrm{CF}_{2} \mathrm{H}$ is 100 times smaller than that for propane, $\mathrm{C}_{3} \mathrm{H}_{8}$. To some degree this scaling should translate to the difference in probability of abstraction of $\mathrm{H}$ from $\mathrm{PP}$ between initial and final fluorination states. Having said that, we need to take into account the intrinsic difference in access by $\mathrm{F}$ atoms to bonded $\mathrm{H}$ atoms on the surface of a polymer as compared with the gas phase. In gas-surface reactions, $\mathrm{F}$ atoms must diffuse into the surface to react with $\mathrm{H}$ atoms that are oriented away from the PP surface. Sites underlying the PP backbone thereby get fluorinated more slowly as compared with sites on top of the PP backbone. The effect is more pronounced for a PP chain underlying the chain on the top surface. As such, if we average the abstraction probabilities over the fluorination depth, the resulting probabilities are smaller than the gas-phase analogs. In our site-balance model, we decreased the abstraction probabilities from the gas-phase analogs to account for $F$ diffusion to underlying sites and hindrance by previously fluorinated sties. For the fully hydrogenated PP backbone, we set the abstraction probabilities of hydrogen from tertiary, secondary, and primary sites as $\mathrm{P}_{\mathrm{T}}=3 \times 10^{-5}$ and $P_{S}=P_{P}=5 \times 10^{-5}$. These values are maximum values for $P_{S}, P_{P}$, and $P_{T}$ in the hierarchy of $H$ abstraction probabilities.

As the transport of fluorine into the film is diffusionlimited, steric hindrance does not play a major role in fluorination of the underlying PP backbone. After F atoms diffuse into the PP network, they are confined between the PP chains thereby having a greater probability to react with adjacent $\mathrm{C}-\mathrm{H}$ bonds. Therefore, the decrease in abstraction probabilities with increasing degree of fluorination is less severe for the underlying PP backbone. The abstraction probability for the last $\mathrm{H}_{\mathrm{T}}$ in a PP unit $\left[-\left(\mathrm{CF}_{2}\right)(\mathrm{CH})\left(\mathrm{CF}_{3}\right)_{-}\right]$ was set to $\mathrm{P}_{\mathrm{T}}=10^{-5}$. The abstractions probabilities for the last $\mathrm{H}_{\mathrm{S}}\left[-(\mathrm{CHF})(\mathrm{CF})\left(\mathrm{CF}_{3}\right)-\right]$ and last $\mathrm{H}_{\mathrm{P}}\left[-\left(\mathrm{CF}_{2}\right)(\mathrm{CF})\left(\mathrm{CHF}_{2}\right)_{-}\right]$ were set to $P_{S}=P_{P}=3 \times 10^{-5}$. As compared with the fully hydrogenated PP, these probabilities are 1.7 times smaller for $\mathrm{P}_{\mathrm{S}}$ and $\mathrm{P}_{\mathrm{P}}$; and three times smaller for $\mathrm{P}_{\mathrm{T}}$. The hierarchy of $\mathrm{F}$ abstraction probabilities is listed in Table 3.

The surface species in our model in different fluorination states, such as $\left[-\left(\mathrm{CH}_{2}\right)(\mathrm{CF})\left(\mathrm{CH}_{3}\right)-\right]$, are grouped into PP repeating units. In this example, $C_{S}$ and $C_{P}$ and $C_{T}$ are in the same PP unit and are bonded to each other. To account for the change in fluorination rates with fluorination depth due to diffusion effects, we allowed that $C_{S}$ and $C_{P}$ can represent segments on different layers of the PP backbone. Though some surface species are still expressed in the form of a PP unit, the $\mathrm{C}$ atoms in them might be on different layers and 
Table 3. Hydrogen abstraction probabilities.

\begin{tabular}{|c|c|c|c|}
\hline Site & Local configuration ${ }^{\text {a) }}$ & Probability & Comment \\
\hline \multirow[t]{7}{*}{$C_{P}$} & \multicolumn{3}{|c|}{$-\left(\mathrm{CH}_{2}\right)(\mathrm{CH})\left(\mathrm{CH}_{3}\right)-+{ }^{\cdot} \mathrm{F}_{g} \rightarrow-\left(\mathrm{CH}_{2}\right)(\mathrm{CH})\left(\mathrm{CH}_{2}^{-}\right)-+\mathrm{HF}_{g}$} \\
\hline & $-\left(\mathrm{CH}_{2}\right)(\mathrm{CH})\left(\mathrm{CH}_{3}\right)-$ & $5 \times 10^{-5}$ & \\
\hline & $-\left(\mathrm{CH}_{2}\right)(\mathrm{CH})\left(\mathrm{CH}_{2} \mathrm{~F}\right)-$ & $5 \times 10^{-5}$ & \\
\hline & $-\left(\mathrm{CH}_{2}\right)(\mathrm{CH})\left(\mathrm{CHF}_{2}\right)-$ & $3 \times 10^{-5}$ & \\
\hline & $-(\mathrm{CHF})(\mathrm{CF})\left(\mathrm{CHF}_{2}^{\circ}\right)-$ & $3 \times 10^{-5}$ & \\
\hline & $-\left(\mathrm{CH}_{2}\right)(\mathrm{CF})\left(\mathrm{CH}_{3}\right)-$ & $2 \times 10^{-5}$ & b) \\
\hline & $-(\mathrm{CHF})(\mathrm{CH})\left(\mathrm{CH}_{3}\right)-$ & $2 \times 10^{-5}$ & b) \\
\hline \multirow[t]{6}{*}{$\mathrm{C}_{\mathrm{S}}$} & \multicolumn{3}{|c|}{$-\left(\mathrm{CH}_{2}\right)(\mathrm{CH})\left(\mathrm{CH}_{3}\right)-+\cdot \mathrm{F}_{g} \rightarrow-\left(\mathrm{CH}^{\cdot}\right)(\mathrm{CH})\left(\mathrm{CH}_{3}\right)-+\mathrm{HF}_{g}$} \\
\hline & $-\left(\mathrm{CH}_{2}\right)(\mathrm{CH})\left(\mathrm{CH}_{3}\right)-$ & $5 \times 10^{-5}$ & \\
\hline & $-(\mathrm{CHF})(\mathrm{CH})\left(\mathrm{CH}_{2} \mathrm{~F}\right)-$ & $3 \times 10^{-5}$ & \\
\hline & $-(\mathrm{CHF})(\mathrm{CF})\left(\mathrm{CH}_{3}\right)-$ & $3 \times 10^{-5}$ & \\
\hline & $-\left(\mathrm{CH}_{2}\right)(\mathrm{CF})\left(\mathrm{CH}_{3}\right)-$ & $2 \times 10^{-5}$ & b) \\
\hline & $-\left(\mathrm{CH}_{2}\right)(\mathrm{CF})\left(\mathrm{CH}_{2} \mathrm{~F}^{\cdot}\right)-$ & $2 \times 10^{-5}$ & b) \\
\hline \multirow[t]{4}{*}{$\mathrm{C}_{\mathrm{T}}$} & \multicolumn{3}{|c|}{$-\left(\mathrm{CH}_{2}\right)(\mathrm{CH})\left(\mathrm{CH}_{3}\right)-+\cdot \mathrm{F}_{g} \rightarrow-\left(\mathrm{CH}_{2}\right)\left(\mathrm{C}^{\cdot}\right)\left(\mathrm{CH}_{3}\right)-+\mathrm{HF}_{g}$} \\
\hline & $-\left(\mathrm{CH}_{2}\right)(\mathrm{CH})\left(\mathrm{CH}_{3}\right)-$ & $3 \times 10^{-5}$ & \\
\hline & $-\left(\mathrm{CH}_{2}\right)(\mathrm{CH})\left(\mathrm{CH}_{2} \mathrm{~F}\right)-$ & $1 \times 10^{-5}$ & b) \\
\hline & $-(\mathrm{CHF})(\mathrm{CH})\left(\mathrm{CH}_{2} \mathrm{~F}\right)-$ & $1 \times 10^{-5}$ & b) \\
\hline
\end{tabular}

a) Only representative configurations for each process are shown. All permutations and combination of surface species are included in the reaction mechanism; ${ }^{b}$ Special case for fully hydrogenated sites with fluorinated C neighbors. See Surface Reaction Mechanism for PP Fluorination.

not bonded to each other in the polymer backbone. As such, some surface species become virtual two-layer species.

Starting with untreated PP, we assigned the first fluorinated $\mathrm{C}$ atom to represent a segment on the topmost layer. The remaining fully hydrogenated $C$ atoms represent segments on the underlying PP backbone. For example, starting with $\left[-\left(\mathrm{CH}_{2}\right)(\mathrm{CH})\left(\mathrm{CH}_{3}\right)-\right]$, if $\mathrm{C}_{\mathrm{S}}$ is first fluorinated, then we assigned that site to the top layer and assigned the fully hydrogenated $C_{P}$ and $C_{T}$ to be on the underlying backbone. So in $\left[-(\mathrm{CHF})(\mathrm{CH})\left(\mathrm{CH}_{3}\right)-\right],(-\mathrm{CHF})$ represents a $\mathrm{C}_{\mathrm{S}}$ segment on the top backbone and the corresponding $\mathrm{P}_{\mathrm{S}}$ was set to $5 \times 10^{-5}\left(\mathrm{P}_{\mathrm{S}}\right.$ in Figure 3$)$. $\left(\mathrm{CH}_{3}\right)$ and $(\mathrm{CH})$ are on the underlying $\mathrm{PP}$ backbone and the corresponding $\mathrm{P}_{\mathrm{P}}$ and $\mathrm{P}_{\mathrm{T}}$ (shown in Figure 3) were set to $2 \times 10^{-5}$ and $10^{-5}$, respectively. Note that the assignment to an underlyinglayer was only applied to fully hydrogenated sites.

In general the rate-limiting step in the fluorination process is the initial abstraction of $\mathrm{H}$ to create an alkyl site. The probability of fluorine addition to an alkyl site should be large compared to that for $\mathrm{H}$ abstraction because of the more negative change in enthalpy of the addition process. Although probabilities for $\mathrm{F}$ addition by $\mathrm{F}_{2}$ reactions are smaller than that by F atoms, and as will be shown below, the flux of $\mathrm{F}_{2}$ incident onto the surface is usually larger than that of $F$. The end result is that the lifetime for surface radical species is short because of passivation by both $\mathrm{F}$ and $\mathrm{F}_{2}$. The fluorination process then follows the sequence of creating one free radical, passivating that radical by $\mathrm{F}$ or $\mathrm{F}_{2}$, followed by creating another free radical.

The likelihood of creating multiple radicals on the same PP repeat unit before passivation occurs is small. Even in the absence of the rapid fluorination of free radicals, the probability for abstracting the second $\mathrm{H}$ in the vicinity of another radical is smaller than abstracting the first $\mathrm{H}$ atom.

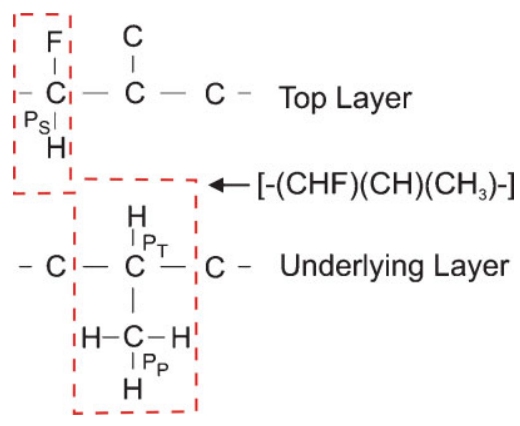

Figure 3. A virtual two-layer surface species is used to address the change in fluorination rates with fluorination depth due to diffusion effects. [CHF] represents a $\mathrm{C}_{\mathrm{S}}$ segment on the topmost backbone. $\left[\mathrm{CH}_{3}\right]$ and $[\mathrm{CH}]$ are on the underlying PP backbone. 
By analogy to related work the rate coefficients for creating second and third radicals in the same gas-phase alkane molecule are usually significantly smaller than for creating the first radical. One such example is the abstraction of $\mathrm{H}$ from methane by $\mathrm{Cl}$ atoms,

$$
\begin{gathered}
\mathrm{CH}_{4}+\cdot \mathrm{Cl} \rightarrow \mathrm{CH}_{3}+\mathrm{HCl} \\
k=9.2 \times 10^{-14} \mathrm{~cm}^{3} \mathrm{~s}^{-1[37]} \\
\\
{ }^{\circ} \mathrm{CH}_{3}+\cdot \mathrm{Cl} \rightarrow \mathrm{HCl}+{ }^{\cdot} \mathrm{CH}_{2} \\
k=3.0 \times 10^{-17} \mathrm{~cm}^{3} \mathrm{~s}^{-1[38]}
\end{gathered}
$$

Based on analogies to these and other reactions, and considering that $\mathrm{F}$ is typically more reactive than $\mathrm{Cl}$, we set surface reaction probabilities for creating the second free radical as being five times smaller than that for the first radical. This applies to reactions that create the second radical on the same $C$ and to reactions that create the second radical in the same PP unit (radicals on different $C$ atoms). We acknowledge that this estimate may exaggerate the decreased propensity for additional radical formation and so provides an upper bound to the reaction probability.

\section{Crosslinking}

Creating adjacent free radicals on the PP backbone enables the possibility of crosslinking reactions. For example, a surface species $\left[-\left(\mathrm{CH}_{2}\right)(\mathrm{CF})\left(\mathrm{CH}_{2}\right)^{-}-\right]\left(\mathrm{D}_{1}\right)$ containing a free radical is produced by $\mathrm{F}$ abstraction. Prior to the passivation of $D_{1}$, a second free radical $\left(D_{2}\right)$ can be produced on an adjacent $P P$ repeating unit $\left[-(\mathrm{CF})(\mathrm{CH})\left(\mathrm{CH}_{3}\right)-\right]$. If $\mathrm{D}_{1}$ and $\mathrm{D}_{2}$ are physically close to each other, they can react and crosslink prior to being passivated by $\mathrm{F}$ atoms,

$$
\begin{gathered}
-\left(\mathrm{CH}_{2}\right)(\mathrm{CF})\left(\mathrm{CH}_{2}^{\circ}\right)-+-(\mathrm{CF})(\mathrm{CH})\left(\mathrm{CH}_{3}\right)- \\
\rightarrow-\left(\mathrm{CH}_{2}\right)(\mathrm{CF})\left[\left(\mathrm{CH}_{2}\right)-(\mathrm{CF})\right](\mathrm{CH})\left(\mathrm{CH}_{3}\right)-
\end{gathered}
$$

Here, two different PP units are crosslinked by the formation of a $\mathrm{C}-\mathrm{C}$ bond $\left[\left(\mathrm{CH}_{2}\right)-(\mathrm{CF})\right]$. Because of the large number of surface species containing radicals and the correspondingly large variety of potential crosslinking products, we generalized the crosslinking reaction of $-\left(\mathrm{CH}_{2}\right)(\mathrm{CF})\left(\mathrm{CH}_{2}^{-}\right)-$as

$$
\begin{aligned}
- & \left(\mathrm{CH}_{2}\right)(\mathrm{CF})\left(\mathrm{CH}_{2}^{\circ}\right)-+M \\
& \rightarrow-\left(\mathrm{CH}_{2}\right)(\mathrm{CF})\left(\mathrm{CRH}_{2}\right)-+M
\end{aligned}
$$

where $M$ represents the density of all surface species containing free radicals. The $\mathrm{R}$ in $\left[-\left(\mathrm{CH}_{2}\right)(\mathrm{CF})\left(\mathrm{CRH}_{2}\right)-\right]$ denotes crosslinking on the corresponding $C_{P}$ site. Note that Equation (14) does not indicate to which PP segment the $C_{P}$ is crosslinked. The rate of Equation (14) is determined by

$$
\text { Rate }=\left[-\left(\mathrm{CH}_{2}\right)(\mathrm{CF})\left(\mathrm{CH}_{2}^{-}\right)-\right][M]\left[N_{\mathrm{PP}}\right] P_{\mathrm{cr}} f_{\mathrm{cr}}
$$

where $\left[-\left(\mathrm{CH}_{2}\right)(\mathrm{CF})\left(\mathrm{CH}_{2}\right)^{-}-\right]$and $[M]$ are the fractional coverages of $-\left(\mathrm{CH}_{2}\right)(\mathrm{CF})\left(\mathrm{CH}_{2}\right)^{-}-$and $M$, respectively, $\left[N_{\mathrm{PP}}\right]$ is the surface density of PP units $\left(10^{15} \mathrm{~cm}^{-2}\right)$, and $f_{\text {cr }}$ is the crosslinking frequency for unity coverage of $M$. As any radical site could potentially crosslink with $\mathrm{M}, P_{c r}$ is the probability that a specific site [- $\left(\mathrm{CH}_{2}\right)(\mathrm{CF})\left(\mathrm{CH}_{2}^{-}\right)$- in this example] will crosslink with $M$. We set $f_{\text {cr }}$ as $10^{3} \mathrm{~s}^{-1}$ for all crosslinking reactions and established a hierarchy for $P_{\mathrm{cr}}$ based on the location on the PP chain and the state of local fluorination.

Free radicals created before $\mathrm{F}$ addition are most likely to be crosslinked since the un-fluorinated PP chain has the smallest steric hindrance. The crosslinking probabilities of the fully hydrogenated $\mathrm{PP}$ chain (except for the radicals) are $P_{\mathrm{cr}}=10^{-2}, 5 \times 10^{-3}, 5 \times 10^{-3}$, for crosslinking on $\mathrm{C}_{\mathrm{P}}, \mathrm{C}_{\mathrm{S}}$, and $C_{T}$ sites, respectively. These values are the largest in the hierarchy of crosslinking probabilities. With addition of $\mathrm{F}$, the site-specific probabilities have the same dependence on the local bonding as the $\mathrm{F}$ abstraction probabilities. For example, $P_{\mathrm{Cr}}$ for $\mathrm{C}_{\mathrm{P}}$ is decreased by a factor of 1.7 to $6 \times 10^{-3}$ for $\left[-\left(\mathrm{CF}_{2}\right)(\mathrm{CF})\left(\mathrm{CF}_{2}\right)-\right]$.

\section{F Addition}

In the gas phase, the addition of an F atom to an alkyl radical is a three-body process and typically has a small effective two-body rate coefficient at low pressure. On the polymer surface, phonons act as the third body so that the reaction probability of $F$ addition can have a high effective two-body rate. To estimate the surface probability, comparisons were made between rates of gas-phase $\mathrm{F}$ addition in the highpressure limit and rates of abstraction by $\mathrm{F}$ atoms. For example,

$$
\begin{aligned}
& \mathrm{CH}_{3}+{ }^{\cdot} \mathrm{F} \rightarrow \mathrm{CH}_{3} \mathrm{~F} \\
& k=9.3 \times 10^{-11} \mathrm{~cm}^{3} \mathrm{~s}^{-1[39]} \\
& \mathrm{CH}_{4}+\cdot \mathrm{F} \rightarrow{ }^{\cdot} \mathrm{CH}_{3}+\mathrm{HF} \\
& k=4.7 \times 10^{-11} \mathrm{~cm}_{\mathrm{s}}^{3-1[40]} \\
& { }^{\mathrm{CF}_{3}}+{ }^{\cdot} \mathrm{F} \rightarrow \mathrm{CF}_{4} \\
& k=2.0 \times 10^{-11} \mathrm{~cm}^{3} \mathrm{~s}^{-1[41]}
\end{aligned}
$$




$$
\begin{aligned}
& \mathrm{CHF}_{3}+{ }^{\cdot} \mathrm{F} \rightarrow{ }^{\cdot} \mathrm{CF}_{3}+\mathrm{HF} \\
& \quad k=3.2 \times 10^{-13} \mathrm{~cm}^{3} \mathrm{~s}^{-1[42]}
\end{aligned}
$$

In general, the rate coefficients for $\mathrm{F}$ addition are larger than the corresponding $\mathrm{H}$-abstraction reactions by $\mathrm{F}$ atoms. There is also less reduction in the rate coefficients for $\mathrm{F}$ addition with increasing $\mathrm{F} / \mathrm{C}$ ratio as compared with $\mathrm{H}$ abstraction. Based on these reference reactions, we set the probability for $\mathrm{F}$ addition at the first alkyl site on any of $C_{P}, C_{S}$, and $C_{T}$ for otherwise fully hydrogenated PP as $10^{-4}$. The hierarchy of $\mathrm{F}$ addition probabilities is shown in Table 4.

Similar techniques were used to determine reaction probabilities for $\mathrm{F}$ addition by $\mathrm{F}_{2}$ at an alkyl radical. For example, gas-phase analogs are,

$$
\begin{aligned}
& \mathrm{C}_{2} \mathrm{H}_{6}+{ }^{\cdot} \mathrm{F} \rightarrow{ }^{\cdot} \mathrm{C}_{2} \mathrm{H}_{5}+\mathrm{HF} \\
& k=1 \times 10^{-10} \mathrm{~cm}^{3} \mathrm{~s}^{-1[43]} \\
& { }^{\circ} \mathrm{C}_{2} \mathrm{H}_{5}+\mathrm{F}_{2} \rightarrow \mathrm{C}_{2} \mathrm{H}_{5} \mathrm{~F}+{ }^{\circ} \mathrm{F} \\
& k=1.3 \times 10^{-11} \mathrm{~cm}^{3} \mathrm{~s}^{-1[43]} \\
& { }^{\circ} \mathrm{CF}_{3}+\mathrm{F}_{2} \rightarrow \mathrm{CF}_{4}+{ }^{\circ} \mathrm{F} \\
& k=1.5 \times 10^{-14} \mathrm{~cm}^{3} \mathrm{~s}^{-1[41]}
\end{aligned}
$$

Comparing these reactions, $\mathrm{F}$ addition by $\mathrm{F}_{2}$ should have smaller probabilities than the abstraction reaction by $\mathrm{F}$. Based on these and other reactions, we scaled probabilities for $\mathrm{F}$ addition by $\mathrm{F}_{2}$ to be five times smaller than those for addition by $\mathrm{F}$ atoms.

\section{Ion Sputtering of PP}

In $\mathrm{Ar} / \mathrm{F}_{2}$ plasmas, the ions incident on the PP film include $\mathrm{Ar}^{+}, \mathrm{F}^{+}$, and $\mathrm{F}_{2}^{+}$. Sputtering differs from abstraction or addition reactions in the ability to ablate $C$ atoms from the PP, thereby changing the structure of the PP surface. Apart from this physical sputtering, $\mathrm{F}^{+}$and $\mathrm{F}_{2}^{+}$are also capable of inducing abstraction or addition reactions. Having said that, for our conditions, the fluxes of $\mathrm{F}$ and $\mathrm{F}_{2}$ neutrals exceed those of the ion fluxes by several orders of magnitude and so we neglected the additional abstraction or addition that might be produced by $\mathrm{F}^{+}$and $\mathrm{F}_{2}^{+}$in addition to their physical sputtering reactions. Sputtering of individual $\mathrm{H}$ atoms by $\mathrm{F}^{+}$and $\mathrm{F}_{2}^{+}$was also neglected as $\mathrm{H}$ abstraction by $\mathrm{F}$ proceeds at rates that are also orders of magnitude higher.

\begin{tabular}{|c|c|c|c|c|}
\hline \multirow[t]{2}{*}{ Site } & \multirow[t]{2}{*}{ Local configuration $^{\text {a) }}$} & \multicolumn{2}{|c|}{ Addition probability by } & \multirow[t]{2}{*}{ Comment } \\
\hline & & $\mathbf{F}$ & $\mathbf{F}_{2}$ & \\
\hline \multirow[t]{5}{*}{$\mathrm{C}_{\mathrm{P}}$} & $-\left(\mathrm{CH}_{2}\right)(\mathrm{CH})\left(\mathrm{CH}_{2}^{\cdot}\right)-$ & $1 \times 10^{-4}$ & $0.2 \times 10^{-4}$ & \\
\hline & $-\left(\mathrm{CH}_{2}\right)(\mathrm{CH})(\mathrm{CHF})-$ & $1 \times 10^{-4}$ & $0.2 \times 10^{-4}$ & \\
\hline & $-\left(\mathrm{CH}_{2}\right)(\mathrm{CH})\left(\mathrm{CF}_{2}\right)-$ & $5 \times 10^{-5}$ & $1 \times 10^{-5}$ & \\
\hline & $-\left(\mathrm{CH}_{2}\right)(\mathrm{CF})\left(\mathrm{CH}_{2}^{-}\right)-$ & $5 \times 10^{-5}$ & $1 \times 10^{-5}$ & b) \\
\hline & $-(\mathrm{CHF})(\mathrm{CH})\left(\mathrm{CH}_{2}^{\cdot}\right)-$ & $5 \times 10^{-5}$ & $1 \times 10^{-5}$ & \\
\hline \multirow[t]{4}{*}{$\mathrm{C}_{\mathrm{S}}$} & $-(\mathrm{CH})(\mathrm{CH})\left(\mathrm{CH}_{3}\right)-$ & $1 \times 10^{-4}$ & $0.2 \times 10^{-4}$ & \\
\hline & $-(\mathrm{CF})(\mathrm{CH})\left(\mathrm{CH}_{3}\right)-$ & $1 \times 10^{-4}$ & $0.2 \times 10^{-4}$ & \\
\hline & $-(\mathrm{CH})(\mathrm{CF})\left(\mathrm{CH}_{3}\right)-$ & $5 \times 10^{-5}$ & $1 \times 10^{-5}$ & b) \\
\hline & $-\left(\mathrm{CH}^{-}\right)(\mathrm{CF})\left(\mathrm{CH}_{2} \mathrm{~F}\right)-$ & $5 \times 10^{-5}$ & $1 \times 10^{-5}$ & \\
\hline \multirow[t]{4}{*}{$\mathrm{C}_{\mathrm{T}}$} & $-\left(\mathrm{CH}_{2}\right)\left(\mathrm{C}^{\prime}\right)\left(\mathrm{CH}_{3}\right)-$ & $1 \times 10^{-4}$ & $0.2 \times 10^{-5}$ & \\
\hline & $-\left(\mathrm{CH}_{2}\right)\left(\mathrm{C}^{\prime}\right)\left(\mathrm{CFH}_{2}\right)-$ & $5 \times 10^{-5}$ & $1 \times 10^{-5}$ & \\
\hline & $-(\mathrm{CHF})(\mathrm{C})\left(\mathrm{CH}_{3}\right)-$ & $5 \times 10^{-5}$ & $1 \times 10^{-5}$ & b) \\
\hline & $-\left(\mathrm{CH}_{2}\right)\left(\mathrm{C}^{\prime}\right)\left(\mathrm{CH}_{2} \mathrm{~F}\right)_{-}$ & $5 \times 10^{-5}$ & $1 \times 10^{-5}$ & b) \\
\hline
\end{tabular}

The sputtering yields of $\mathrm{C}$ from the PP backbone as a function of energy for $\mathrm{Ar}^{+}$and $\mathrm{F}^{+}$were estimated using SRIM. $^{[44]}$ The SKM uses a general form of ion-energydependent reaction probability,

$$
Y(E)=p_{\circ} \frac{E^{n}-E_{\mathrm{th}}^{n}}{E_{\mathrm{r}}^{n}-E_{\mathrm{th}}^{n}}
$$

Table 4. Fluorine addition probabilities.

\footnotetext{
a) Only representative configurations for each process are shown. All permutations and combination of surface species are included in the reaction mechanism; ${ }^{\text {b) }}$ Special case. See Surface Reaction Mechanism for PP Fluorination.
} 
where $Y(E)$ is the sputtering yield at ion energy $E$, $p_{\mathrm{o}}$ the yield at reference energy $E_{\mathrm{r}}$, and $E_{\mathrm{th}}$ is the threshold energy. Results from SRIM were fitted to the form of Equation (23). For the same ion energy, the sputtering yields of $C$ atoms by $\mathrm{Ar}^{+}$or $\mathrm{F}^{+}$incident on PTFE were typically higher than the yields for PP, as PTFE has a more favorable mass ratio with the incident ion. To simplify the mechanism, we used sputtering yields for PTFE as an approximation for sputtering of $C_{T}$ and $C_{S}$ in all fluorination states. When a $\mathrm{C}$ atom is sputtered, we assumed that the $\mathrm{F}$ and $\mathrm{H}$ atoms initially bonded to that $C$ atom remain bonded and thus also leave the PP surface. We also assumed that sputtering of $\mathrm{C}_{\mathrm{T}}$ also removes the $\mathrm{CH}_{3}$ bonded to it. Although this simplification exaggerates sputtering at low $\mathrm{F} / \mathrm{C}$ ratios, it captures the removal of the top surface layer by ion bombardment and the subsequent exposure of the fresh underlying hydrocarbons. The sputtering parameters used in Equation (23) are shown in Table 5. Because of lack of fundamental data, we assumed that $\mathrm{F}_{2}^{+}$has the same sputtering yields as $\mathrm{Ar}^{+}$because the molecular weights of the two ions are similar.

For example, a typical sputtering reaction of a nearly fully fluorinated PP segment is,

$$
\begin{aligned}
& -\left(\mathrm{CF}_{2}\right)(\mathrm{CF})\left(\mathrm{CHF}_{2}\right)-+\cdot \mathrm{F}_{g}^{+} \\
& --\left(\mathrm{CH}_{2}\right)(\cdot \mathrm{CF})\left(\mathrm{CHF}_{2}\right)-+\cdot \mathrm{CF}_{2 g}+\mathrm{F}_{g} \\
& -\left(\mathrm{CH}_{2}\right)(\cdot \mathrm{CF})\left(\mathrm{CHF}_{2}\right)-+\cdot \mathrm{F}_{g} \\
& \rightarrow-\left(\mathrm{CH}_{2}\right)\left(\mathrm{CF}_{2}\right)\left(\mathrm{CHF}_{2}\right)-
\end{aligned}
$$

where $C_{S}$ (with two $F$ atoms attached) is ablated and the underlying $\mathrm{C}_{\mathrm{S}}$ (with two $\mathrm{H}$ atoms attached) is exposed to the plasma. Since the $\mathrm{CH}_{2}$ functional group actually lies on the layer underneath $-(\mathrm{CF})\left(\mathrm{CHF}_{2}\right)-$, the latter species contains a chain-end on the first layer having a free radical. Since the PP polymer is likely to be randomly oriented at the surface with respect to the alignment of the PP backbones, sputtering of, for example, $C_{S}$ may in fact expose, $C_{P}, C_{S}$, or $C_{T}$ in the underlying chain. For simplicity and consistency we assumed that removal of $C_{\mathrm{T}}$ (together with attached methyl group) or $\mathrm{C}_{\mathrm{S}}$ will expose the same type of site in the underlying layer. For surface species that contain segments on different layers, we expect that the $C$ atoms on the underlying layer are less likely to be sputtered because of shielding from the top layer. As a result, we only considered sputtering of $C$ atoms on the top layer.

Because of the expected large neutral fluxes compared to ion fluxes, the free radicals produced by ion bombardment will likely be quickly passivated by $\mathrm{F}$ or $\mathrm{F}_{2}$. We represented the passivation process in Equation (25) by adding an additional $\mathrm{F}$ atom to the initial $\mathrm{C}_{\mathrm{T}}$ to terminate the chain. Although this is an approximation for our conditions, it facilitated the elimination of many hundreds of reactions in our mechanism with little loss of accuracy. This rapid passivation of free radicals also hinders the plasma from reaching the exposed hydrocarbon on the underlying layer. As a result, we assumed that the abstraction and additions rates on the second underlying layer are 100 times slower than the rates on the surface layer given the same state of fluorination. The rapid passivation, producing short lifetimes for surface free radical sites, enables us to ignore the sputtering of free radicals thereby eliminating an additional set of reactions with little loss of accuracy.

Ion bombardment can also ablate short-chain molecules from the polymer surface. For example, short-chain fragments containing up to $20 \mathrm{CH}_{2}$ units have been observed following bombardment of PE by $\mathrm{Ar}^{+} .{ }^{[13]}$ In our reaction mechanism, short-chain ablation is represented by the removal of a length of the backbone cleaved at the bonds between the $C_{S}$ and $C_{T}$ atoms. Removal of this chain then exposes fresh PP backbone on the underlying layer. The exposed PP backbone, as an untreated PP surface, continues to react with the gas-phase species.

\section{Photon-Induced Reactions}

In $\mathrm{Ar} / \mathrm{F}_{2}$ discharges, VUV photons incident onto the PP primarily result from the resonance states of $\mathrm{Ar}(105 \mathrm{~nm})$ and $\mathrm{F}(95 \mathrm{~nm})$ and by electronic transitions in $\mathrm{F}_{2}(157 \mathrm{~nm})$.

Table 5. Coefficients for sputtering yields $Y(E)=p_{\mathrm{o}}\left(\left(E^{n}-E_{\mathrm{th}}^{n}\right) /\left(E_{\mathrm{r}}^{n}-E_{\mathrm{th}}^{n}\right)\right)$.

\begin{tabular}{llllll}
\hline Ion & \multicolumn{1}{c}{ Site } & $\boldsymbol{p}_{\text {o }}$ & $\boldsymbol{E}_{\mathbf{r}}$ & $\boldsymbol{E}_{\text {th }}$ & $\boldsymbol{N}$ \\
\hline $\mathrm{F}^{+}$ & $\mathrm{C}_{\mathrm{P}}$ & 0.12 & 150 & 30 & 1.2 \\
$\mathrm{~F}^{+}$ & $\mathrm{C}_{\mathrm{S}}, \mathrm{C}_{\mathrm{T}}$ & 0.05 & 150 & 40 & 1.2 \\
$\mathrm{~F}^{+}$ & Short-chain desorption & 0.12 & 150 & 40 & 1.2 \\
$\mathrm{Ar}^{+}, F_{2}^{+}$ & $\mathrm{C}_{\mathrm{P}}$ & 0.04 & 150 & 30 & 2.0 \\
$\mathrm{Ar}^{+}, F_{2}^{+}$ & $\mathrm{C}_{\mathrm{S}}, \mathrm{C}_{\mathrm{T}}$ & 0.016 & 150 & 40 & 2.0 \\
$\mathrm{Ar}^{+}, F_{2}^{+}$ & Short-chain desorption & 0.04 & 150 & 40 & 2.0
\end{tabular}


Quantum yields for photon-induced reactions on PP are available for the resonance transition in Xe at $147 \mathrm{~nm}^{\text {[22-24] }}$ For example, VUV irradiation abstracts $\mathrm{H}_{2}$ from a PP backbone and forms a double bond,

$$
\begin{aligned}
& -\left(\mathrm{CH}_{2}\right)(\mathrm{CH})\left(\mathrm{CH}_{3}\right)-+\mathrm{h} v(147 \mathrm{~nm}) \\
& \rightarrow \mathrm{H}_{2 \mathrm{~g}}+-(\mathrm{CH})=(\mathrm{C})\left(\mathrm{CH}_{3}\right)- \\
& p=0.25
\end{aligned}
$$

where $p$ is the quantum yield. ${ }^{[22]}$ For partially fluorinated $\mathrm{PP}$, we assumed that $\mathrm{H}_{2}$ will be extracted if both tertiary and secondary $\mathrm{H}$ atoms are available on a PP unit; $\mathrm{F}_{2}$ will be extracted if all tertiary and secondary $\mathrm{H}$ atoms have been substituted by F atoms; and HF will be extracted for other cases.

VUV irradiation can also sever $\mathrm{C}-\mathrm{C}$ bonds and allow for disproportionation reactions. Dorofeev et al. determined that a representative process is,

$$
\begin{aligned}
2[ & \left.-\left(\mathrm{CH}_{2}\right)(\mathrm{CH})\left(\mathrm{CH}_{3}\right)-\right]+h v(147 \mathrm{~nm}) \\
& \rightarrow-\left(\mathrm{CH}_{2}\right)\left(\mathrm{CH}_{2}\right)\left(\mathrm{CH}_{3}\right)+\left(\mathrm{CH}_{2}\right) \\
& =(\mathrm{C})\left(\mathrm{CH}_{3}\right)- \\
p & =0.25
\end{aligned}
$$

where two chain-ending units are produced. ${ }^{[22]}$ The quantum yield for this process is about 0.25 at $147 \mathrm{~nm}$.

The ablation of methyl radicals can also occur under VUV irradiation,

$$
\begin{aligned}
& -\left(\mathrm{CH}_{2}\right)(\mathrm{CH})\left(\mathrm{CH}_{3}\right)-+h v(147 \mathrm{~nm}) \\
& \rightarrow-\left(\mathrm{CH}_{2}\right)(\mathrm{CH})-+\mathrm{CH}_{3 g} \\
& p=0.025
\end{aligned}
$$

where the yield is smaller than ablation of $\mathrm{H}_{2}$ by an order of magnitude. ${ }^{[22]}$

With the increase in fluorination, the quantum yields for these photon-surface reactions decrease due to the stronger $\mathrm{C}-\mathrm{F}$ bonds and the steric hindrance of the $\mathrm{F}$ atoms. For example, the quantum yield for F abstraction from PTFE at $147 \mathrm{~nm}$ is only about 0.0025 . The hierarchy for photonsurface reaction probabilities used in the model is shown in Table 6. We used the measured yields at $147 \mathrm{~nm}$ as approximations for those at $157 \mathrm{~nm}$. To obtain the quantum yields at 95 and $105 \mathrm{~nm}$, we further assumed that quantum yields are linearly proportional to photon energy. In the Ar/ $\mathrm{F}_{2}$ discharges considered here, the fluxes of photons onto the film are usually several orders of magnitude lower than the fluxes of $\mathrm{F}$ atoms. Consequently, the ablation of single $\mathrm{H}$ or $\mathrm{F}$ atoms by VUV photons was neglected because $\mathrm{H}$ abstraction by $\mathrm{F}$ atoms and passivation of free radicals by $\mathrm{F}$ and $F_{2}$ proceed at rates that are expected to be orders of magnitude larger. Photon induced crosslinking was also neglected for the same reason.

Double bonds resulting from the VUV illumination are likely to be rapidly passivated by $\mathrm{F}$ atoms and $\mathrm{F}_{2}$ molecules. To estimate this probability, comparisons were made between rates of gas-phase double bond passivation reactions in the high-pressure limit and rates of passivation of free radicals [Equation (16)],

$$
\begin{aligned}
& \mathrm{C}_{2} \mathrm{H}_{4}+\mathrm{F} \rightarrow \mathrm{C}_{2} \mathrm{H}_{4} \mathrm{~F} \\
& k=1.7 \times 10^{-10} \mathrm{~cm}^{3} \mathrm{~s}^{-1[45]}
\end{aligned}
$$

In general, the rates of double bond passivation by $\mathrm{F}$ atoms are similar to the rates of $\mathrm{F}$ passivation of free radicals. Consequently, we set the probability for passivation of double bonds by $\mathrm{F}$ atoms to $10^{-4}$ regardless of fluorination state.

\section{Plasma Properties of $\mathrm{Ar} / \mathrm{F}_{2}$ Plasma}

A schematic of the reactor implemented in the model is shown in Figure 4. This is a two-dimensional simulation in Cartesian coordinates. The square electrodes are $46 \mathrm{~cm}$ on a side (and so the depth perpendicular to the plane of the simulation is $46 \mathrm{~cm}$ ). The upper electrode is powered at $10 \mathrm{MHz}$ through a blocking capacitor and the lower electrode is grounded. Both electrodes serve as showerheads with discrete nozzles for gas introduction and are surrounded by dielectric having $\varepsilon / \varepsilon_{0}=8.0$. All other surfaces in the reactor are grounded metal including the pump port at the right boundary of the reactor. The gap between the electrodes is $2.54 \mathrm{~cm}$. The PP film is placed in the middle of the reactor. Unprocessed PP film is fed from the left side of the reactor and the film moves from left to right through the reactor, thereby achieving continuous treatment. The film is treated as an electrically floating dielectric. The base conditions are $\mathrm{Ar} / \mathrm{F}_{2}=60 / 40$ (by volume) at 500 mTorr, a flow rate of $600 \mathrm{sccm}$, and a power deposition of $600 \mathrm{~W}$ $\left(0.28 \mathrm{~W} \cdot \mathrm{cm}^{-2}\right.$ of electrode area or $0.11 \mathrm{~W} \cdot \mathrm{cm}^{-3}$ of interelectrode volume). The applied voltage is adjusted to yield this power. The web moves at $9 \mathrm{~cm} \cdot \mathrm{s}^{-1}$, which produces a $6 \mathrm{~s}$ residence time in the reactor.

The resulting rf cycle-averaged electron temperature $\left(T_{\mathrm{e}}\right)$, ionization by bulk electrons $\left(S_{\mathrm{b}}\right)$, and ionization by secondary beam electrons $\left(S_{\mathrm{eb}}\right)$ for these conditions are shown in Figure $4 b-d$. For $600 \mathrm{~W}$, the applied rf potential is $296 \mathrm{~V}$ in amplitude, producing a dc bias of $11 \mathrm{~V}$. This slightly positive dc bias is developed as the area of the powered 
Table 6. Probabilities for photon-surface reactions.

Process $^{\text {a) }}$

Probability

\begin{tabular}{lll}
\hline 95 & 105 & $\mathbf{1 5 7}$ \\
\cline { 2 - 2 } & $\mathbf{n m}$ & \\
\hline 0.41 & 0.375 & 0.25 \\
0.41 & 0.375 & 0.25 \\
0.013 & 0.012 & 0.008
\end{tabular}

Scission and disproportionation

$$
\begin{aligned}
& -\left(\mathrm{CH}_{2}\right)(\mathrm{CH})\left(\mathrm{CH}_{3}\right)-+h v \rightarrow-\left(\mathrm{CH}_{2}\right)\left(\mathrm{CH}_{2}\right)\left(\mathrm{CH}_{3}\right) \\
& -\left(\mathrm{CH}_{2}\right)(\mathrm{CH})\left(\mathrm{CH}_{3}\right)-+h v \rightarrow\left(\mathrm{CH}_{2}\right)=(\mathrm{C})\left(\mathrm{CH}_{3}\right)- \\
& -(\mathrm{CHF})(\mathrm{CF})\left(\mathrm{CH}_{3}\right)-+h v \rightarrow-(\mathrm{CHF})\left(\mathrm{CF}_{2}\right)\left(\mathrm{CH}_{3}\right) \\
& -(\mathrm{CHF})(\mathrm{CF})\left(\mathrm{CH}_{3}\right)-+h v \rightarrow(\mathrm{CHF})=(\mathrm{C})\left(\mathrm{CH}_{3}\right)-
\end{aligned}
$$

0.0045

0.005

0.0045

\section{$\underline{\text { Abaltion of } \mathrm{C}_{\mathrm{P}}}$}

$$
-\left(\mathrm{CH}_{2}\right)(\mathrm{CH})\left(\mathrm{CH}_{3}\right)-+h v \rightarrow \mathrm{CH}_{3 g}+-\left(\mathrm{CH}_{2}\right)(\mathrm{CH})-
$$

a) Only example processes are shown here. All permutations and combination of surface species are included in the reaction mechanism.


Figure 4. Geometry for the reactor used in the model and plasma properties for the base case $\left(\mathrm{Ar} / \mathrm{F}_{2}=60 / 40,500 \mathrm{mTorr}, 600 \mathrm{sccm}, 600 \mathrm{~W}\right.$ at $10 \mathrm{MHz}$ and web speed of $\left.9 \mathrm{~cm} \cdot \mathrm{s}^{-1}\right)$. (a) Geometry, (b) electron temperature, (c) ionization by bulk electrons, $\mathrm{S}_{\mathrm{b}}$, (d) ionization by sheath-accelerated beam electrons, $\mathrm{S}_{\mathrm{eb}}$. The feed and collector rolls are not included here as they are outside of the plasma volume. The PP film enters through the left side of the reactor and translates to the right. The intervening dielectric produces a layered structure in $T_{\mathrm{e}}$. The bulk ionization source peaks near the electrode edges because of the elevated $T_{\mathrm{e}}$ from electric field enhancement. The bulk and beam ionization are plotted on log scales over two decades. The maximum value or range of values in each frame is noted. electrode is equal to that of grounded surface and the plasma is highly electronegative. The $T_{\mathrm{e}}$ in the bulk plasma is $3 \mathrm{eV}$. The intervening dielectric produces a layered structure in the $T_{\mathrm{e}}$, higher above the dielectric adjacent to the sheath at the upper electrode, as a result of the dc bias and larger sheath potential. Because of the large capacitance of the thin PP film, it acquires a floating potential, though not instantaneously during the rf cycle. This allows for some sheath oscillation at the sheath boundary and a higher $T_{\mathrm{e}}$ of $3.5 \mathrm{eV}$. The distribution of $T_{\mathrm{e}}$ in the bulk plasma is more uniform as a result of Ohmic heating and a large thermal conductivity. Local maxima in $T_{\mathrm{e}}$ occur near the edges of the electrodes because of electric field enhancement.

With $T_{\mathrm{e}}$ nearly uniform in the bulk plasma, the rate of ionization by bulk electrons largely follows the electron density and has a maximum value of $9.8 \times 10^{17} \mathrm{~cm}^{-3} \cdot \mathrm{s}^{-1}$. Ionization sources peak near the electrode edges because of the elevated $T_{\mathrm{e}}$ resulting from the electric field enhancement. With the 
sheath 1-2 mm thick, and the mean free path for electron collisions being longer than the sheath width, secondary electrons are launched into the bulk plasma from the upper electrode with essentially the instantaneous sheath potential. The sheath potential on the upper electrode has a maximum value of approximately $V_{\text {rf }}-V_{\mathrm{dc}}$ or $285 \mathrm{~V}$. The mean free path for electrons at this energy is about $1.0 \mathrm{~cm}$, close to electrode-film spacing of $1.3 \mathrm{~cm}$. As a result, the secondary electrons undergo at most one or two collisions and produce little ionization (maximum value $2.6 \times 10^{15} \mathrm{~cm}^{-3} \mathrm{~s}^{-1}$ ) before intersecting and charging the film.

The cycle-averaged electron density [e], negative ion density $\left[\mathrm{F}^{-}\right]$, total positive ion density [total ions], and plasma potential are shown in Figure $5 \mathrm{a}-\mathrm{d}$. [e] with a peak value of $1.3 \times 10^{10} \mathrm{~cm}^{-3}$ closely mirrors the bulk ionization source and has a maximum near the edge of the electrode. $F_{2}$ rapidly attaches electrons and the mean free path of electrons for attachment is about $2 \mathrm{~cm}$, commensurate to the electrodefilm gap. Electrons are therefore as likely to be lost by attachment as by diffusion to surfaces. Negative ions cannot climb the ambipolar potential barrier and so are restricted to the core of the plasma. As a result, the loss of negative ions is dominated by volumetric processes (ion-ion neutralization and associative detachment) and there are time-averaged electrostatic traps for negative ions in the bulk plasma. The end result is that the peak value of $\left[\mathrm{F}^{-}\right]$is $2.0 \times 10^{11} \mathrm{~cm}^{-3}$ and the reactor-averaged electronegativity $\left(\left[\mathrm{F}^{-}\right] /[\mathrm{e}]\right)$ is about 15 . Note that the spatial locations at which the electron, negative ion and positive ion densities have their peak values are different. As a result, their maximum values may differ even while quasi-neutrality is being maintained.

The cycle-averaged densities of $\mathrm{F}_{2}$ and $\mathrm{F}$ are shown in Figure $5 \mathrm{e}, \mathrm{f}$. The reactor averaged $\left[\mathrm{F}_{2}\right]$ and $[\mathrm{F}]$ are $3.9 \times 10^{15}$ and $2.0 \times 10^{15} \mathrm{~cm}^{-3}$, respectively, representing a dissociation fraction of 0.2. The distribution of $\mathrm{F}$ atoms is fairly uniform because of the low reactivity of $\mathrm{F}$ atoms on previously passivated surfaces. Injection of the $\mathrm{Ar} / \mathrm{F}_{2}$ mixture through discrete nozzles produces local minima in $[F]$, where the feedstock gases jet into the reactor, and corresponding peaks in the feedstock density. $\left[\mathrm{F}_{2}\right]$ also has a rather uniform distribution with a slightly lower value in the center of the plasma where the dissociation rates are higher. The higher value of $\left[\mathrm{F}_{2}\right]$ near the electrodes or the PP results from associative desorption.
As discussed above, surface reactions of the PP sheet with the $\mathrm{Ar} / \mathrm{F}_{2}$ plasma produce gas species such as $\mathrm{HF}$ (from $\mathrm{F}$ abstraction reactions) and fragments of the PP chain $\left(\mathrm{C}_{n} \mathrm{H}_{m}\right.$ from ion and photon bombardment). HF is relatively stable - all chemical reactions of HF with the gas phase species in this system are highly endothermic. On a reactor averaged basis, the HF density is $1.8 \times 10^{12} \mathrm{~cm}^{-3}$, sufficiently small to neglect the consequences of electron impact reactions with HF on electron transport. Hydrocarbon fragments of the PP chain from ion and photon bombardment were neglected in the gas phase reaction mechanism due to their low rates of production. The most likely reactions they would undergo are the same as on the surface, $\mathrm{H}$ atom abstraction by $\mathrm{F}$ atoms, which would not significantly affect the fluxes to the substrate.

\section{Plasma Fluorination of PP}

\section{Surface Characteristics for the Base Case}

With the PP immersed in the plasma, both sides of the film are fluorinated. For purposes of presentation, the path 
followed when plotting surface quantities starts at the left end of the reactor on the bottom side of the PP film, then turns the corner on the right end, and finally continues on the same side of the PP film, back to the left end of the reactor (see Figure 4a). Following this path, fluxes of neutrals, ions, and photons incident on the PP film for the base case are shown in Figure 6. The fluxes of $\mathrm{F}$ and $\mathrm{F}_{2}$ are essentially uniform on both sides of the film. As the dissociation fraction of $F_{2}$ was found to be 0.2 , the flux of $F_{2}$, $4.3 \times 10^{19} \mathrm{~cm}^{-2} \cdot \mathrm{s}^{-1}$, is about 1.5 times that of $\mathrm{F}$. These fluxes of neutrals are four orders of magnitude larger than those of the ions $\left(\mathrm{Ar}^{+}, \mathrm{F}^{+}, \mathrm{F}_{2}^{+}\right)$. As such, the influence of ions will be dominantly through processes that have threshold energies (such as sputtering) as opposed to the competing contributions to abstraction or passivation. The flux of $\mathrm{Ar}^{+}$ $\left(1.5 \times 10^{15} \mathrm{~cm}^{-2} \cdot \mathrm{s}^{-1}\right)$ exceeds that of $\mathrm{F}_{2}^{+}$(by three times) and $\mathrm{F}^{+}$(by six times), resulting in part from the higher mole fraction of $\mathrm{Ar}$ in the feedstock and the lower ionization potential of $\mathrm{Ar}(15.8 \mathrm{eV})$ relative to $\mathrm{F}(17.4 \mathrm{eV})$, while being commensurate to $F_{2}(15.7 \mathrm{eV})$.

In addition to direct ionization, multistep ionization from excited states is an appreciable source of $\mathrm{Ar}^{+}$and provides for the more uniform distribution of $\mathrm{Ar}^{+}$. The top of the film (in Figure 4a) faces the powered electrode and so has line-ofsight to the electric-field-enhanced corners of the electrodes. The peaks in the flux of $\mathrm{F}_{2}^{+}$on the top of the film, resulting dominantly from single-step electron-impact ionization, reflects the higher ionization sources at the edge of the electrodes. The flux of $\mathrm{Ar}^{+}$, having more distributed sources due to multistep ionization, has smaller peaks.

The fluxes of VUV photons are a few times $10^{13} \mathrm{~cm}^{-2} \cdot \mathrm{s}^{-1}$ and thus are $10^{6}$ times smaller than that of the F flux and $10^{2}$ times smaller than that of the ion flux. As such, photons are of secondary importance in determining the composition of the surface with the exception of processes unique to photons, such as initiating double-bond formation. The edge effect on the top of the film is more severe for the photon fluxes. Although there is some trapping of the VUV radiation (a trapping factor of 5.8 for resonance radiation from $\mathrm{F}$ and 5.0 for Ar), much of the VUV flux arrives at the substrate following line-of-sight transport from its source, and so mirrors the larger source functions at the edges.

The energy and angular distributions (IEADs) summed for all ions incident on the top and bottom PP surfaces are shown in Figure 7. The corresponding plasma potential at $30 \mathrm{~cm}$ is also shown in Figure 7 at approximately the peak of the anodic cycle (phase $\varphi=\pi / 2$ ), peak of the cathodic cycle $(\varphi=3 \pi / 2)$, and the zero crossings in the rf voltage displaced by $V_{\text {dc }}$. The rf amplitude is $296 \mathrm{~V}$ to deliver a power of $600 \mathrm{~W}$. The top side of the film faces the powered electrode. In spite of being a floating dielectric, the capacitance of the PP film is large enough that a significant rf drift current is collected with an accompanying cathodic sheath on the top side
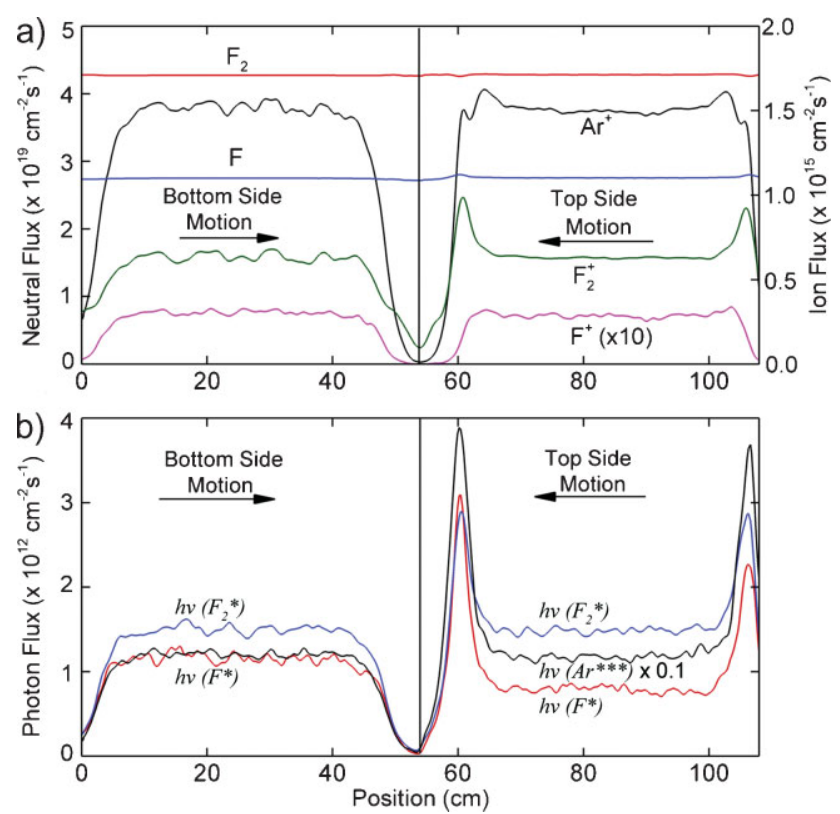

Figure 6. Fluxes incident on the PP film for the base case ( $\mathrm{Ar} /$ $\mathrm{F}_{2}=60 / 40,500 \mathrm{mTorr}, 600 \mathrm{sccm}, 600 \mathrm{~W}$ at $10 \mathrm{MHz}$ and web speed of $\left.9 \mathrm{~cm} \cdot \mathrm{s}^{-1}\right)$. (a) Neutrals and ions and (b) VUV photons. Fluxes of $\mathrm{F}$ and $\mathrm{F}_{2}$ are generally four orders of magnitude larger than ion fluxes $\left(\mathrm{Ar}^{+}, \mathrm{F}^{+}, \mathrm{F}_{2}^{+}\right)$. Photon fluxes are several orders of magnitude lower than the fluxes of neutrals and ions.

when the top electrode is the anode. During the cathodic part of the cycle for the top electrode, the film discharges and there is virtually no sheath. As the pressure is relatively high (500 mTorr), charge-exchange collisions (with collision frequencies on the order of $10^{7} \mathrm{~s}^{-1}$ ) effectively degrade IEADs in energy. With the exception of the increased energy due to the positive dc bias, the IEAD incident on the bottom side of the PP is similar to that on the top side.

If the film were stationary in the discharge, film surface properties would be a function of position in the discharge reflecting the spatial distribution of reactants. With a moving web, each site on the film averages the spatial distribution of fluxes as that site moves under the fluxes from entry to exit points. The film is ultimately uniformly processed with a surface composition given by those sites exiting the reactor. Exceptions include differences in fluxes incident on the top and bottom sides of the film. This is not to say that the spatial distributions of the fluxes are not important. As the surface composition of the film changes, so does the reactivity of the film. For example, a given ratio of radical-to-ion fluxes at the entry of the film to the reactor may elicit a different response than that at the exit of the reactor since the surface composition will have changed. Having said that, the trends in surface coverages on the top and bottom sides of the film are largely the same due to the magnitudes of the neutral fluxes and IEADs being similar. Typically, the PP film surface compositions at the exit of the 


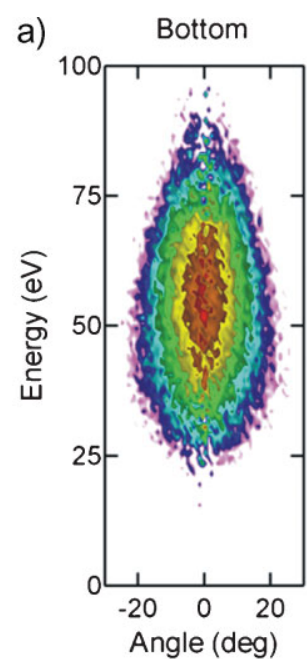

b)

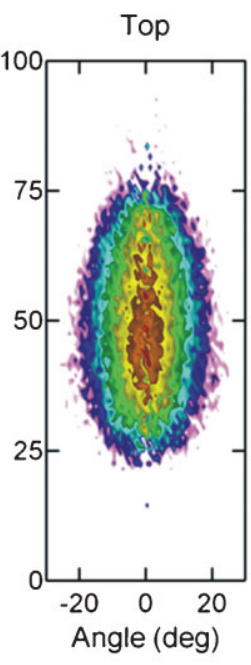

MIN $=$ MAX

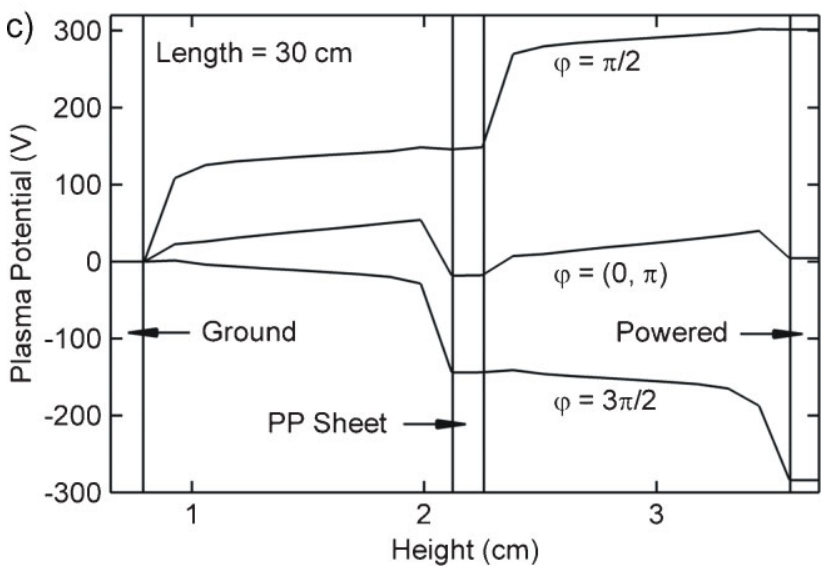

Figure 7. IEADs striking the PP surfaces for the base case and the corresponding plasma potential $\left(\mathrm{Ar} / \mathrm{F}_{2}=60 / 40,500 \mathrm{mTorr}\right.$, $600 \mathrm{sccm}, 600 \mathrm{~W}$ at $10 \mathrm{MHz}$ and web speed of $9 \mathrm{~cm} \cdot \mathrm{s}^{-1}$ ). (a) IEADs incident on the bottom surface, (b) IEADs incident on the top surface, and (c) plasma potential as a function of height at different phases during an $\mathrm{rf}$ cycle (position $=30 \mathrm{~cm}$ ). The contours for the IEADs span two decades using a log scale.

reactor differ by less than $10 \%$ between the top and bottom surfaces. As such, surface properties will be discussed for only the bottom side.

The coverage of surface species (PP units in various fluorination states) on the bottom side of the film are shown in Figure 8a,b for the first $10 \mathrm{~cm}$ of the film travel into the reactor. This corresponds to a treatment time of $1.1 \mathrm{~s}$. The sequential nature of the fluorination is shown by the change in fractional surface coverages as a function of distance (which corresponds to time). In the first $2 \mathrm{~cm}$, the surface species [aside from the untreated $\mathrm{PP}$, $\left.\left(\mathrm{CH}_{2}\right)(\mathrm{CH})\left(\mathrm{CH}_{3}\right)\right]$ having the largest coverages are those containing a single free radical on $\mathrm{C}_{\mathrm{P}}\left[\left(\mathrm{CH}_{2}\right)(\mathrm{CH})\left(\mathrm{CH}_{2}\right)\right], \mathrm{C}_{\mathrm{S}}$ $\left[(\mathrm{CH})(\mathrm{CH})\left(\mathrm{CH}_{3}\right)\right]$, and $\mathrm{C}_{\mathrm{T}}\left[\left(\mathrm{CH}_{2}\right)\left(\mathrm{C}^{\circ}\right)\left(\mathrm{CH}_{3}\right)\right]$. These corre-
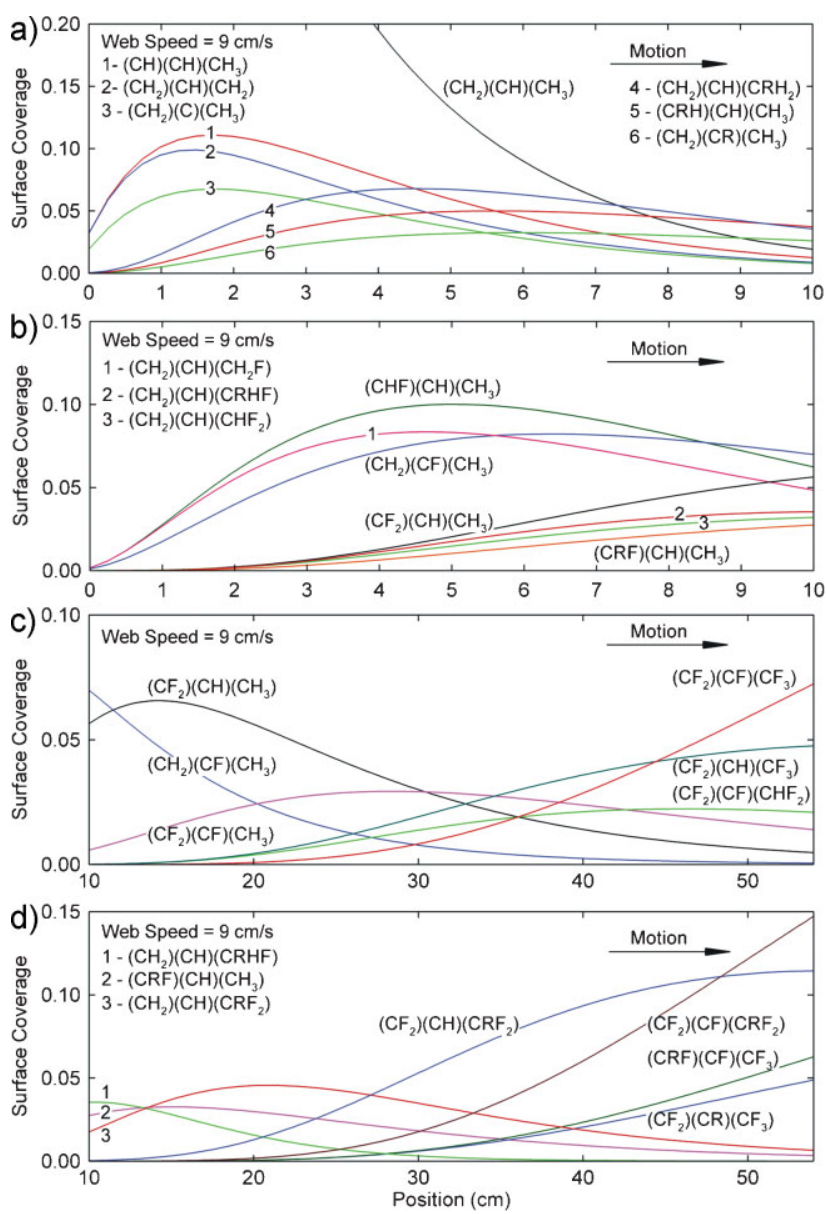

Figure 8. Coverages of sites on the bottom side of the PP film for the base case $\left(\mathrm{Ar} / \mathrm{F}_{2}=60 / 40,500 \mathrm{mTorr}, 600 \mathrm{sccm}, 600 \mathrm{~W}\right.$ at $10 \mathrm{MHz}$ and web speed of $9 \mathrm{~cm} \cdot \mathrm{s}^{-1}$ ) as a function of position. $(a, b)$ First $10 \mathrm{~cm}(1.1 \mathrm{~s})$ of the film entry into the reactor. (c, d) Between 10 (1.1 s) and $54 \mathrm{~cm}$ (the end of the film, a residence time of $6 \mathrm{~s}$ ) The surface species with largest fractional coverage at the exit of the film from the reactor is the perfluorinated PP unit with crosslinking on $\mathrm{C}_{\mathrm{P}}$ [denoted by $\left(\mathrm{CF}_{2}\right)(\mathrm{CF})\left(\mathrm{CRF}_{2}\right)$ ]. 
increase in the fractional coverages of sites having a single $\mathrm{F}$ atom and where $\mathrm{C}_{\mathrm{P}}, \mathrm{C}_{\mathrm{S}}$, or $\mathrm{C}_{\mathrm{T}}$ are crosslinked $\left[\left(\mathrm{CH}_{2}\right)(\mathrm{CR})\left(\mathrm{CH}_{3}\right),(\mathrm{CRH})(\mathrm{CH})\left(\mathrm{CH}_{3}\right),\left(\mathrm{CH}_{2}\right)(\mathrm{CH})\left(\mathrm{CRH}_{2}\right)\right]$. The sum of the coverages of these crosslinked sites peaks at about 0.15 between 4 and $6 \mathrm{~cm}(0.44-0.67 \mathrm{~s})$. Further fluorination, and ion and photon activated processes, monotonically decrease these fully hydrogenated crosslinked sites beyond $6 \mathrm{~cm}(0.67 \mathrm{~s})$.

The decrease in fully hydrogenated alkyl sites also maps onto an increase in the fractional coverages of sites in which a single $\mathrm{F}$ atom has been substituted for $\mathrm{H}$ in the starting PP $\left[\left(\mathrm{CH}_{2}\right)(\mathrm{CH})\left(\mathrm{CH}_{2} \mathrm{~F}\right),(\mathrm{CHF})(\mathrm{CH})\left(\mathrm{CH}_{3}\right),\left(\mathrm{CH}_{2}\right)(\mathrm{CF})\left(\mathrm{CH}_{3}\right)\right]$. The sum of these singly fluorinated sites peaks at about 0.26 between 4 and $6 \mathrm{~cm}(0.44-0.67 \mathrm{~s})$. The fluorination of these alkyl sites by $\mathrm{F}$ and $\mathrm{F}_{2}$ compete with ion bombardment or photolysis, which potentially removes the $\mathrm{F}$ atom, and abstraction, which produces new free radicals. The abstraction and addition reactions also replace $\mathrm{H}$ atoms with $\mathrm{F}$ atoms on fully hydrogenated crosslinked sites and so that surface species such as $\left(\mathrm{CH}_{2}\right)(\mathrm{CH})(\mathrm{CRHF})$ and (CRF) $(\mathrm{CH})\left(\mathrm{CH}_{3}\right)$ are produced. The fractional coverage of these species is less than that of the singly fluorinated sites without crosslinking and peak at about 0.03 between 10 and $15 \mathrm{~cm}(1.1-1.7 \mathrm{~s})$, as shown in Figure $8 \mathrm{~b}$ and d. (Note that the parenthetical times following distances into the reactor represent the residence time of the film in the reactor at those points.)

The abstraction of the second $\mathrm{H}$ atom, which produces a free radical in a singly fluorinated backbone, potentially generates a large number of species. For example, the second $\mathrm{H}$ abstraction after a first fluorination on $\mathrm{C}_{\mathrm{P}}$ can result in three species: $\left(\mathrm{CH}_{2}\right)(\mathrm{CH})(\mathrm{CHF}),\left(\mathrm{CH}_{2}\right)\left(\mathrm{C}^{\circ}\right)\left(\mathrm{CH}_{2} \mathrm{~F}\right)$, and $(\mathrm{CH})(\mathrm{CH})\left(\mathrm{CH}_{2} \mathrm{~F}\right)$. These radicals are quickly passivated, producing doubly fluorinated sites that increase to fractional coverages of $0.01-0.1$ by $10 \mathrm{~cm} \quad(1.1 \mathrm{~s})$ $\left[\left(\mathrm{CH}_{2}\right)(\mathrm{CH})\left(\mathrm{CHF}_{2}\right)\right.$ and $\left(\mathrm{CF}_{2}\right)(\mathrm{CH})\left(\mathrm{CH}_{3}\right)$ in Figure $\left.8 \mathrm{~b}\right]$. Concurrent to the increase in the coverages of sites having radicals or $\mathrm{F}$ atoms, the coverage of pure hydrocarbon sites $\left[\left(\mathrm{CH}_{2}\right)(\mathrm{CH})\left(\mathrm{CH}_{3}\right)\right]$ undergoes an exponential decrease. Within the first $10 \mathrm{~cm}(1.1 \mathrm{~s})$ the fractional coverage of the untreated PP decreases to 0.03 .

Due to the steric hindrance and the decrease in reaction rates with increase in fluorination, the fluorination to higher $\mathrm{F} / \mathrm{C}$ ratios proceeds at a slower rate. This is shown in Figure 8c,d for surface coverages between 10 (1.1 s) and $54 \mathrm{~cm}$ (the exit of the reactor, corresponding to a residence time of $6 \mathrm{~s}$ ). The doubly fluorinated sites on the $\mathrm{C}_{\mathrm{P}}$ and $\mathrm{C}_{\mathrm{S}}$ sites, $\left[\left(\mathrm{CF}_{2}\right)(\mathrm{CH})\left(\mathrm{CH}_{3}\right),\left(\mathrm{CH}_{2}\right)(\mathrm{CH})\left(\mathrm{CRF}_{2}\right)\right]$, have maximum coverage between 10 and $20 \mathrm{~cm}(1.1-2.2 \mathrm{~s})$. As additional abstraction and passivation reactions take place, a large variety of species are produced. For example, the triply fluorinated sites having the earliest and largest fractional coverage is $\left(\mathrm{CF}_{2}\right)(\mathrm{CF})\left(\mathrm{CH}_{3}\right)$, peaking at $30 \mathrm{~cm}(3.3 \mathrm{~s})$. Following this sequence of abstraction and fluorination, the fully fluorinated PP unit $\left[\left(\mathrm{CF}_{2}\right)(\mathrm{CF})\left(\mathrm{CF}_{3}\right)\right]$ achieves a fractional coverage of 0.07 at the exit. The precursors for the fully fluorinated sites are dominantly $\left(\mathrm{CF}_{2}\right)(\mathrm{CF})\left(\mathrm{CHF}_{2}\right)$ and $\left(\mathrm{CF}_{2}\right)(\mathrm{CH})\left(\mathrm{CF}_{3}\right)$. As the fully fluorinated sites do not significantly react with neutral gas-phase species, they lose $\mathrm{C}$ and $\mathrm{F}$ atoms dominantly by ion or photon bombardment.

Crosslinking consumes two adjacent alkyl groups and so eliminates the possibility of passivation by $\mathrm{F}$ or $\mathrm{F}_{2}$. Crosslinking is therefore in competition to the fluorination process. This role of cross-linking in this competition is indicated by the large coverage of $\left(\mathrm{CF}_{2}\right)(\mathrm{CF})\left(\mathrm{CRF}_{2}\right)$ at the exit of the reactor ( 0.15 at $54 \mathrm{~cm}$ or $6 \mathrm{~s}$ ). Other crosslinked PP sites having relatively large coverages at $54 \mathrm{~cm}$ are $\left(\mathrm{CF}_{2}\right)(\mathrm{CH})\left(\mathrm{CRF}_{2}\right), \quad(\mathrm{CRF})(\mathrm{CF})\left(\mathrm{CF}_{3}\right)$, and $\left(\mathrm{CF}_{2}\right)(\mathrm{CR})\left(\mathrm{CF}_{3}\right)$, with fraction coverages ranging from 0.05 to 0.12 . At the exit of the reactor, the modeled $\mathrm{F} / \mathrm{C}$ ratio of the PP surface is 1.39 .

The more slowly fluorinated sites [e.g., $\left(\mathrm{CF}_{2}\right)(\mathrm{CH})\left(\mathrm{CF}_{3}\right)$, $\left.\left(\mathrm{CF}_{2}\right)(\mathrm{CH})\left(\mathrm{CRF}_{2}\right)\right]$ take longer to fully fluorinate because of the reduction in rates of both $\mathrm{H}$ abstraction and passivation accounting for diffusion of gas-phase radicals into the film. As discussed earlier, the $\mathrm{CH}$ groups in $\left(\mathrm{CF}_{2}\right)(\mathrm{CH})\left(\mathrm{CF}_{3}\right)$ and $\left(\mathrm{CF}_{2}\right)(\mathrm{CH})\left(\mathrm{CRF}_{2}\right)$ are located on the underlying PP backbones, thereby having more resistance to $\mathrm{H}$ abstraction. The dominant surface species having $\mathrm{H}$ that is left on the top PP surface after $6 \mathrm{~s}$ is $\left(\mathrm{CF}_{2}\right)(\mathrm{CF})\left(\mathrm{CHF}_{2}\right)$. The last $\mathrm{H}_{\mathrm{P}}$ is the most difficult to be abstracted because of deactivation effects and steric hindrance. At the exit of the film, only about 0.04 of the original inventory of $\mathrm{H}$ atoms are left on the top surface. All other $\mathrm{H}$ atoms were abstracted by $\mathrm{F}$ atoms with the resulting radical sites either passivated by a $\mathrm{F}$ atom or crosslinked.

The consequences of ion and photon bombardment, though small as a fraction of the total reactivity, tend to produce more stable species that integrate in density as the film moves through the plasma. The end result is that those species have non-negligible densities at the exit of the reactor. As with the neutral channels, reactions of ions and photons are capable of producing many hundreds of other types of sites. Although any single site has a small density, cumulative densities can be non-negligible. The cumulative contributions of reactions initiated by ions and photons to fluorination are shown in Figure 9a. The separate contributions from ions and photons are shown in Figure 9b,c. The total coverage of surface species resulting from both ions and photons having only $1 \mathrm{~F}$ atom peaks at $10^{-3}$ at $12 \mathrm{~cm}$ $(1.3 \mathrm{~s})$ and decreases monotonically thereafter. The total coverages of surface species containing $3-6 \mathrm{~F}$ atoms increase monotonically in the first $48 \mathrm{~cm}$ while the total coverages of species containing $2 \mathrm{~F}$ atoms largely remain constant at $2 \times 10^{-3}$.

Beyond $48 \mathrm{~cm}(5.3 \mathrm{~s})$, the fluxes of ions and photons incident on the PP film quickly decrease as the PP film translates out of the discharge. Due to the rapid neutral 

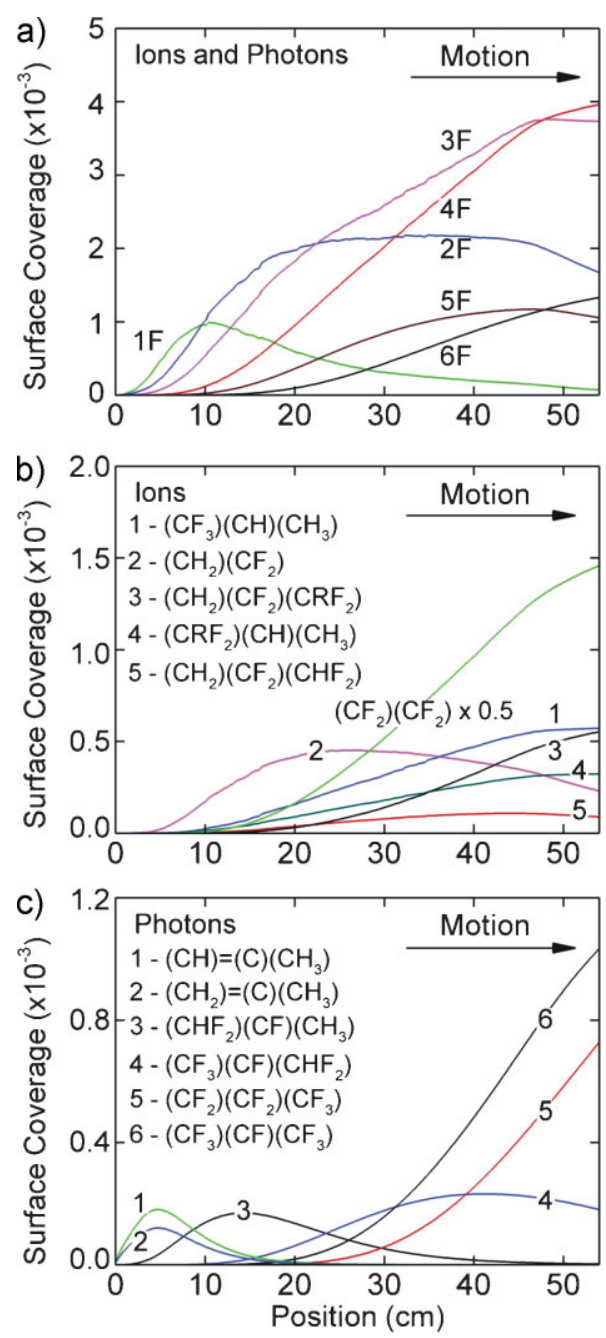

Figure 9. Effects of ion sputtering and VUV illumination for the base case $\left(\mathrm{Ar} / \mathrm{F}_{2}=60 / 40,500 \mathrm{mTorr}, 600 \mathrm{sccm}, 600 \mathrm{~W}\right.$ at $10 \mathrm{MHz}$ and web speed of $9 \mathrm{~cm} \cdot \mathrm{s}^{-1}$ ) as a function of position. (a) Cumulative coverages of sites containing $1-6 \mathrm{~F}$ atoms resulting from ion sputtering and photon-activated processes. Major surface species resulting from (b) ion bombardment and (c) VUV irradiation.

diffusion out of the discharge, the fluxes of $\mathrm{F}$ and $\mathrm{F}_{2}$ remain largely unchanged while the plasma density decreases. Reactions initiated by ions and photons thereby decrease whereas those by $\mathrm{F}$ and $\mathrm{F}_{2}$ do not significantly diminish. As a result, the total coverages of species resulting from ion and photon bombardment containing 1 and $2 \mathrm{~F}$ atoms decrease as further fluorination by neutrals promotes them to species having 3-6 $\mathrm{F}$ atoms. At the exit of the reactor, most surface species resulting from reactions of ions and photons contain 3 or $4 \mathrm{~F}$ atoms. The sum of the fractional coverages of all these sites is 0.01 at the exit of the film.

The coverages of surface species resulting from ion bombardment, shown in Figure 9b, is first dominated by $\left(\mathrm{CH}_{2}\right)\left(\mathrm{CF}_{2}\right)$, which reaches a maximum of $5 \times 10^{-4}$ at $24 \mathrm{~cm}$
$(2.7 \mathrm{~s})$, and decreases thereafter because of further fluorination. At the exit of the reactor, the dominant species resulting from sputtering is $\left(\mathrm{CF}_{2}\right)\left(\mathrm{CF}_{2}\right)$, with a fractional coverage of $3 \times 10^{-3} \cdot\left(\mathrm{CF}_{2}\right)\left(\mathrm{CF}_{2}\right)$ results from the ablation of methyl groups (in all fluorination states) by ion or photon bombardment. This produces a radical on $\mathrm{C}_{\mathrm{T}}$, which is passivated by a $\mathrm{F}$ atom. For example, removal of $\left(\mathrm{CH}_{2} \mathrm{~F}\right)$ from $\left(\mathrm{CF}_{2}\right)(\mathrm{CF})\left(\mathrm{CH}_{2} \mathrm{~F}\right)$ produces $\left(\mathrm{CF}_{2}\right)(\mathrm{CF})$, which forms $\left(\mathrm{CF}_{2}\right)\left(\mathrm{CF}_{2}\right)$ following passivation. Ablation of the methyl group can also produce precursors to $\left(\mathrm{CF}_{2}\right)\left(\mathrm{CF}_{2}\right)$. For example, ablation of $\left(\mathrm{CHF}_{2}\right)$ from $\left(\mathrm{CH}_{2}\right)(\mathrm{CF})\left(\mathrm{CHF}_{2}\right)$ forms $\left(\mathrm{CH}_{2}\right)(\mathrm{CF})$. The subsequent passivation results in the formation of $\left(\mathrm{CH}_{2}\right)\left(\mathrm{CF}_{2}\right)$. Further fluorination sequentially produces (CHF) $\left(\mathrm{CF}_{2}\right)$ and $\left(\mathrm{CF}_{2}\right)\left(\mathrm{CF}_{2}\right)$. Note that VUV irradiation also ablates methyl groups, which can lead to the same species. For our conditions the amount of $\left(\mathrm{CF}_{2}\right)\left(\mathrm{CF}_{2}\right)$ resulting from VUV irradiation is no more than half that from ions.

Unlike ablation of the $C_{P}$ methyl groups, ablation of $C_{S}$ or $\mathrm{C}_{\mathrm{T}}$, with the attached $\mathrm{H}, \mathrm{F}$, or $\mathrm{C}$ atoms, exposes fresh underlying PP backbone. In our site-balance model, this is represented by a species (nominally a PP unit) that contains segments on the top and underlying layers. A likely sequence of events is the following: consider the initial PP unit $\left(\mathrm{CF}_{2}\right)(\mathrm{CH})\left(\mathrm{CH}_{3}\right)$ where the $\mathrm{C}_{\mathrm{T}}$ and the accompanying $\mathrm{C}_{\mathrm{P}}$ methyl group, $(\mathrm{CH})\left(\mathrm{CH}_{3}\right)$, are sputtered. This leaves the $\mathrm{C}_{\mathrm{S}}$ chain end, $-\left(\mathrm{CF}_{2}\right)$, on the top layer that, following passivation, becomes $-\left(\mathrm{CF}_{3}\right)$. The removal of $\mathrm{C}_{\mathrm{T}}$ and $C_{P}$ exposes the same groups on the lower layer, producing, as viewed from the plasma, $\left(\mathrm{CF}_{3}\right)(\mathrm{CH})\left(\mathrm{CH}_{3}\right)$. The F-atom passivation that terminates the chain on the top layer is a steric hindrance to the fresh $(\mathrm{CH})\left(\mathrm{CH}_{3}\right)$ exposed on the lower level thereby reducing the rate of fluorination of the $(\mathrm{CH})\left(\mathrm{CH}_{3}\right)$. Since the top layer tends to be highly fluorinated because of the high reactivity of the chain-end free radical, it is also less likely to further react. The end result is that $\left(\mathrm{CF}_{3}\right)(\mathrm{CH})\left(\mathrm{CH}_{3}\right)$ and $\left(\mathrm{CH}_{2}\right)\left(\mathrm{CF}_{2}\right)\left(\mathrm{CHF}_{2}\right)$, another two-layer species, have surface coverages at the exit of the reactor, $6 \times 10^{-4}$ and $2 \times 10^{-4}$, respectively, as shown in Figure 9b. Crosslinking $\left[\left(\mathrm{CRF}_{2}\right)(\mathrm{CH})\left(\mathrm{CH}_{3}\right)\right.$ and $\left(\mathrm{CH}_{2}\right)\left(\mathrm{CF}_{2}\right)$ $\left.\left(\mathrm{CRF}_{2}\right)\right]$ can occur prior to or after sputtering. Ion-induced crosslinking has a surface coverage below $6 \times 10^{-4}$ at the exit of the reactor.

The coverage of surface species produced by VUV irradiation is shown in Figure 9c. In the first $6 \mathrm{~cm}$ of the reactor, the major photon-activated process is the extraction of $\mathrm{H}_{2}$ from the fully hydrogenated PP backbone with the generation of double-bonded carbon $(\mathrm{CH})=(\mathrm{C})\left(\mathrm{CH}_{3}\right)$ and $\left(\mathrm{CH}_{2}\right)=(\mathrm{C})\left(\mathrm{CH}_{3}\right)$ (a chain end species), whose coverages peak at $2.0 \times 10^{-4}$ and $1.0 \times 10^{-4}$, respectively, at about $6 \mathrm{~cm}$. Unsaturated sites resulting from the extraction of $\mathrm{HF}$ or $\mathrm{F}_{2}$ have even lower coverages due to the slower extraction rates. The photon-activated disproportionation reaction breaks the PP backbone into short chains with the 
generation of chain-ending species (all species except $(\mathrm{CH})=(\mathrm{C})\left(\mathrm{CH}_{3}\right)$ in Figure 9c). The sum of the coverages of these chain-ending species is about 0.003 at the exit. These relatively low coverages are caused by the low magnitudes of photon fluxes as compared with that of neutrals and ions. A secondary contributing cause to these low coverages is that these chain-ending species are more rapidly removed by ion and photon bombardment because of lower surface binding energies. (To ablate these species, only one $\mathrm{C}-\mathrm{C}$ bond needs to be broken.)

The coverages of crosslinked species are shown in Figure 10a. The free radicals on $C_{P}$ have larger crosslinking probabilities as $C_{P}$ protrudes from the $\mathrm{PP}$ chain and so the majority of crosslinking occurs on $C_{P}$. At the exit of the reactor, the fully fluorinated crosslinked $\mathrm{C}_{\mathrm{P}}\left[\left(\mathrm{CF}_{2}\right)(\mathrm{CF})\left(\mathrm{CRF}_{2}\right)\right]$ has the largest (and still increasing) coverage at 0.15. This increase largely results from the fluorination of the precursors of $\left(\mathrm{CF}_{2}\right)(\mathrm{CF})\left(\mathrm{CRF}_{2}\right) \quad\left[\left(\mathrm{CF}_{2}\right)(\mathrm{CH})\left(\mathrm{CRF}_{2}\right), \quad(\mathrm{CHF})(\mathrm{CF})\right.$ $\left(\mathrm{CRF}_{2}\right)$, and $\left.\left(\mathrm{CF}_{2}\right)(\mathrm{CF})(\mathrm{CRHF})\right]$ after crosslinking. The coverage of fully fluorinated crosslinked $\mathrm{C}_{\mathrm{S}}$ sites $\left[(\mathrm{CRF})(\mathrm{CF})\left(\mathrm{CF}_{3}\right)\right]$ and $\mathrm{C}_{\mathrm{T}}$ sites $\left[\left(\mathrm{CF}_{2}\right)(\mathrm{CR})\left(\mathrm{CF}_{3}\right)\right]$ are 0.06 and 0.05 at $54 \mathrm{~cm}(6 \mathrm{~s})$, respectively.

The coverages of the sum of crosslinked $C_{P}, C_{S}$, and $C_{T}$ sites are shown in Figure 10b. As number of sites with free radicals decreases with increase in degree of fluorination, most of crosslinking occurs in the first $30 \mathrm{~cm}(3.3 \mathrm{~s})$. The exit coverage of crosslinked $C_{P}$ sites (0.4) is about twice that of the $C_{S}$ sites and four times that of the $C_{T}$ sites. The sum of coverages of all crosslinked sites is about 0.73 at $54 \mathrm{~cm}(6 \mathrm{~s})$, which is about 70 times larger than the sum of all sites formed due to ion and photon bombardment. Note that, within our modeled system, crosslinked $C_{P}$ is bonded to two $\mathrm{C}$ atoms whereas $\mathrm{C}_{\mathrm{S}}$ and $\mathrm{C}_{\mathrm{T}}$ are bonded to 3 and $4 \mathrm{C}$ atoms, respectively. Crosslinking, which connects free radicals to adjacent $C$ atoms, eliminates those bonds from being fluorinated. Crosslinking therefore competes with the $\mathrm{F}$ addition process, reducing the maximum possible $\mathrm{F} / \mathrm{C}$ ratio from that of a fully fluorinated backbone. At the same time, crosslinked sites are also more resistive to ion sputtering and VUV photolysis, processes that potentially remove $\mathrm{C}-\mathrm{F}$ bonds from the surface. So depending on operating conditions, crosslinking could also be beneficial to the fluorination process. For the process conditions investigated in this work, the C/F ratio is generally decreased by crosslinking.

The fractional coverages of $\mathrm{CH}$ and $\mathrm{CF}_{n}$ functional groups as a function of position are shown in Figure 11a. $\beta$-C refers to $C$ atoms that do not have $\mathrm{C}-\mathrm{F}$ bonds but have neighboring $\mathrm{C}$ atoms that do have $\mathrm{C}-\mathrm{F}$ bonds. (This type of species is discernable by XPS.) For example, $\left(\mathrm{CH}_{2}\right)$ and $\left(\mathrm{CH}_{3}\right)$ are $\beta-\mathrm{C}$ species in $\left(\mathrm{CH}_{2}\right)(\mathrm{CF})\left(\mathrm{CH}_{3}\right)$. The coverage of singly fluorinated sites (CF) saturates in the first $10 \mathrm{~cm}$ (residence time of $1.1 \mathrm{~s}$ ) because of the rapid fluorination of fully hydrogenated PP on the top layer. The fluorination of
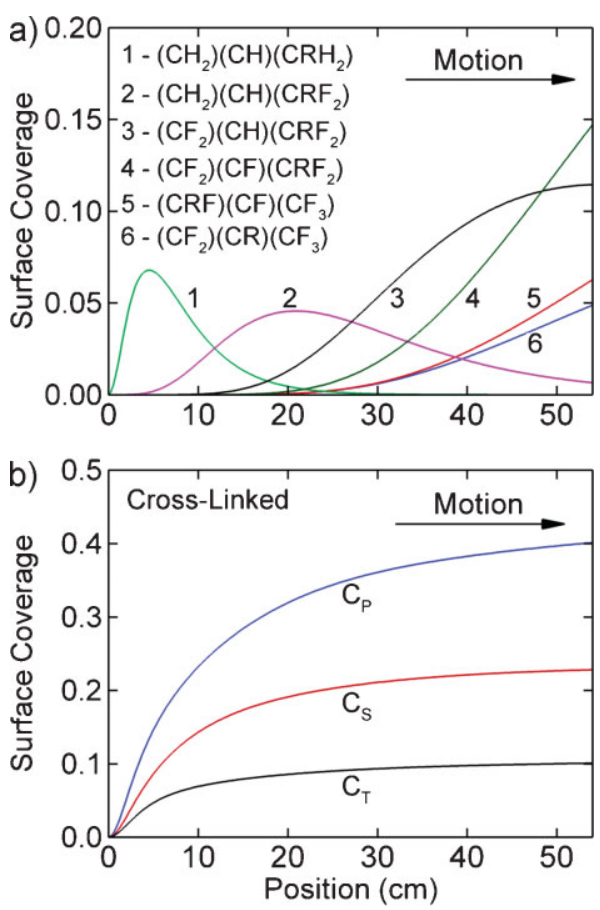

Figure 10. Consequences of crosslinking for the base case ( $\mathrm{Ar} /$ $\mathrm{F}_{2}=60 / 40,500 \mathrm{mTorr}, 600 \mathrm{sccm}, 600 \mathrm{~W}$ at $10 \mathrm{MHz}$ and web speed of $9 \mathrm{~cm} \cdot \mathrm{s}^{-1}$ ) as a function of position. (a) Major crosslinked species and (b) coverages of the sum of PP unit sites with crosslinked $C_{P}, C_{S}$, and $C_{T}$.

exposed PP on the underlying layers (producing $\mathrm{CF}$ ) and the fluorination of $\mathrm{CF}$ to higher states (consuming $\mathrm{CF}$ ) proceed at slower rates and are at a near equilibrium from 10 to $54 \mathrm{~cm}(1.1-6 \mathrm{~s})$.

The fluorination first produces a peak coverage of 0.33 for $\beta-C$ sites at about $15 \mathrm{~cm}(1.6 \mathrm{~s})$, decreasing thereafter. As a result of steric hindrance, and electrophilic and diffusion effects, the fractions of doubly and triply fluorinated sites $\left(\mathrm{CF}_{2}\right.$ and $\left.\mathrm{CF}_{3}\right)$ increase at slower rates. The fraction of $\mathrm{CF}_{2}$ sites begins to saturate at the exit with a coverage of 0.37 , mainly consisting of perfluorinated $C_{S}$ and doubly fluorinated $C_{P}$ sites. The general scaling for the $F / C$ ratio, shown in Figure $11 \mathrm{~b}$, is for a more rapid fluorination during the first $15 \mathrm{~cm}(1.7 \mathrm{~s})$, here to a value of 0.5 , caused by the single fluorination of fully hydrogenated PP. This relatively rapid fluorination is followed by a slower approach toward 1.39 over the rest of the treatment. This latter, and slower, fluorination results from the double and triple fluorination of $C_{S}$ and $C_{P}$ sites and from the reactions with the lowerlayer PP chains.

A comparison of computed and experimental results for functional group surface coverages after $6 \mathrm{~s}$ of treatment is given in Table $7{ }^{[27]}$ The prediction for $\mathrm{F} / \mathrm{C}$ ratio agrees well with the experiment. The discrimination between $\mathrm{CH}$ and $\beta$-C in our model is somewhat arbitrary because of the finite 

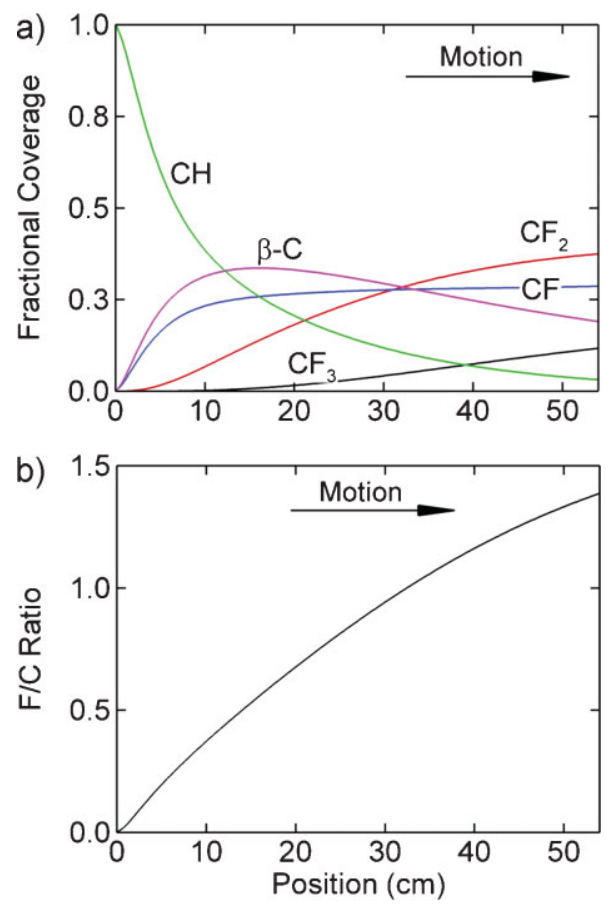

Figure 11. Functionalization of the bottom surface of the PP film for the base case $\left(\mathrm{Ar} / \mathrm{F}_{2}=60 / 40,500 \mathrm{mTorr}, 600 \mathrm{sccm}, 600 \mathrm{~W}\right.$ at $10 \mathrm{MHz}$ and web speed of $9 \mathrm{~cm} \cdot \mathrm{s}^{-1}$ ) as a function of position. (a) Coverage of functional groups and (b) F/C ratio. The sequential nature of the fluorination is shown by the successive dominance of $\mathrm{CF}_{n}$ with larger $n$ as the film translates downstream.

number of configurations that we are able to model. If we instead compare the sum of $\mathrm{CH}$ and $\beta-\mathrm{C}$ with experiment, the agreement is better. The overestimation of $\mathrm{CF}$ and underestimation of $\mathrm{CF}_{3}$ most likely originate from the approximate manner in which $\mathrm{F}$ atom diffusion into the surface layers is addressed. Another source of discrepancy is that the F/C ratios obtained from the experimental ESCA measurements arise from analysis of the outermost $6-8 \mathrm{~nm}$ of the surface, which does not directly correspond to the effective depth addressed in the simulation.

\section{Exposure Time}

To investigate the effects of longer exposure time on the surface composition while minimizing the changing of other parameters, the web speed was reduced to about $2 \mathrm{~cm} \cdot \mathrm{s}^{-1}$ to enable a residence time of $26 \mathrm{~s}$ to match experiments. ${ }^{[27]}$ Surface coverages for the major surface species are shown in Figure 12a. At the exit of the reactor, $54 \mathrm{~cm}(26 \mathrm{~s})$, the dominant surface species is $\left(\mathrm{CF}_{2}\right)(\mathrm{CF})\left(\mathrm{CRF}_{2}\right)$, the fully fluorinated PP unit with crosslinking on $C_{P}(0.41$ coverage). The coverage of the fully fluorinated $\mathrm{PP}$ backbone $\left(\mathrm{CF}_{2}\right)(\mathrm{CF})\left(\mathrm{CF}_{3}\right)$ reaches saturation at about 0.2 after $30 \mathrm{~cm}$ (14.3s). Other dominant surface species include fully fluorinated PP units with crosslinking on $\mathrm{C}_{\mathrm{S}}\left[(\mathrm{CRF})(\mathrm{CF})\left(\mathrm{CF}_{3}\right)\right]$ and $\mathrm{C}_{\mathrm{T}}\left[\left(\mathrm{CF}_{2}\right)(\mathrm{CR})\left(\mathrm{CF}_{3}\right)\right]$. So with a longer exposure time, apart from fluorination, the dominant changes in surface composition still result from crosslinking.

As the hydrogenated PP becomes fluorinated, the rates of fluorine addition decrease while the effects of ion and photon bombardment continue to integrate. This integration is demonstrated by the nearly linear increase in coverage of $\left(\mathrm{CF}_{2}\right)\left(\mathrm{CF}_{2}\right)$ from 0 to $48 \mathrm{~cm}(0-23 \mathrm{~s})$. Recall that $\left(\mathrm{CF}_{2}\right)\left(\mathrm{CF}_{2}\right)$ is formed by the ablation of the methyl group (for all fluorination states). Beyond $48 \mathrm{~cm}(23 \mathrm{~s})$, the film translates out of the discharge and the fluxes of ions and photons decrease rapidly so that the surface coverage of $\left(\mathrm{CF}_{2}\right)\left(\mathrm{CF}_{2}\right)$ remains nearly constant beyond $48 \mathrm{~cm}(23 \mathrm{~s})$.

The fractional coverages of functional groups and the $\mathrm{F} / \mathrm{C}$ ratio are shown in Figure $12 \mathrm{~b}, \mathrm{c}$. The persistence of small fractions of $\mathrm{CH}(0.005)$ results from the ablation of $\mathrm{C}_{\mathrm{S}}$ and $\mathrm{C}_{\mathrm{T}}$ groups by ion bombardment and the slow rates of fluorination of the fresh underlying PP backbone. In the absence of sputtering, photolysis, and crosslinking, we would expect $\mathrm{CF}, \mathrm{CF}_{2}$, and $\mathrm{CF}_{3}$ to each have $1 / 3$ of the

Table 7. Comparison of modeled surface coverage and experimental ESCA F/C atomic ratios.

Bonding Surface fractional coverage and $F / C^{a)}$

\begin{tabular}{|c|c|c|c|}
\hline \multicolumn{2}{|c|}{$6 \mathrm{~s}$ Treatment } & \multicolumn{2}{|c|}{26 s Treatment } \\
\hline Simulation & Experiment & Simulation & Experiment \\
\hline 0.03 & 0.12 & 0.01 & 0.02 \\
\hline 0.19 & 0.18 & 0.04 & 0.10 \\
\hline 0.29 & 0.26 & 0.35 & 0.30 \\
\hline 0.37 & 0.34 & 0.42 & 0.45 \\
\hline 0.12 & 0.10 & 0.18 & 0.13 \\
\hline 1.38 & 1.41 & 1.73 & 1.57 \\
\hline
\end{tabular}

a) Operating conditions: $\mathrm{Ar} / \mathrm{F}_{2}=60 / 40,600 \mathrm{~W}, 500 \mathrm{mTorr}$, web speed $=9 \mathrm{~cm} \cdot \mathrm{s}^{-1}(6 \mathrm{~s})$ and $2 \mathrm{~cm} \cdot \mathrm{s}^{-1}(26 \mathrm{~s})$. 

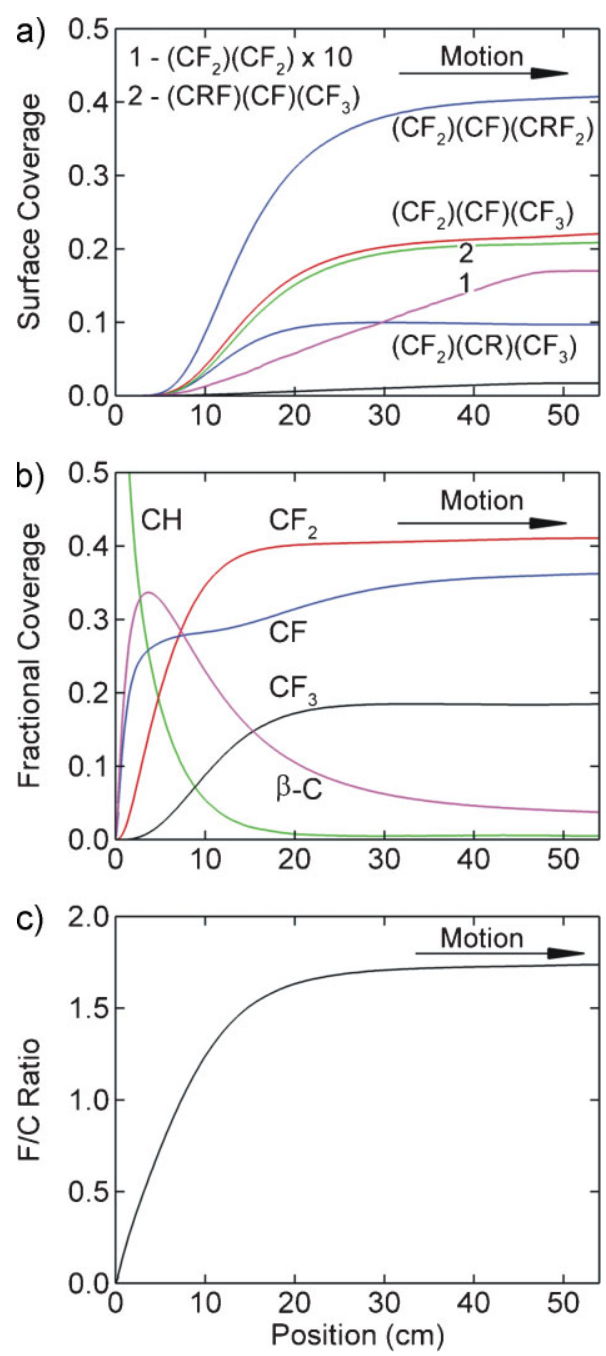

Figure 12. Functionalization of the bottom surface of the PP film as a function of position for $26 \mathrm{~s}$ treatment with a web speed of $2 \mathrm{~cm} \cdot \mathrm{s}^{-1}$. The conditions are otherwise same as the base case (Ar/ $F_{2}=60 / 40,500 \mathrm{mTorr}, 600 \mathrm{sccm}, 600 \mathrm{~W}$ at $10 \mathrm{MHz}$ ). (a) Coverage of surface species, (b) coverages of functional groups, and (c) F/C ratio.

fractional coverage at the exit. The dominance of $\mathrm{CF}_{2}(0.42$ coverage) is largely attributed to the crosslinking of $C_{P}$ sites, which eliminates the possibility of $\mathrm{CF}_{3}$ groups. The crosslinking of $\mathrm{C}_{\mathrm{T}}$ converts it to a $\beta$-C site by eliminating the possibility of $\mathrm{F}$ attachment and this conversion contributes to the high coverage $\beta-C(0.04)$ at the exit of the reactor. The crosslinked $\mathrm{C}_{\mathrm{T}}$ sites have no $\mathrm{F}$ or $\mathrm{H}$ bonding and are bonded to only other $\mathrm{C}$ atoms.

The $\mathrm{F} / \mathrm{C}$ ratio first undergoes a rapid increase in the first $20 \mathrm{~cm}(9.5 \mathrm{~s})$, then stabilizes at about 1.7 between 20 and $54 \mathrm{~cm}(9.5-26 \mathrm{~s})$. This stabilization can be attributed to two effects. First, the top PP surface is highly fluorinated and crosslinked after the first $20 \mathrm{~cm}(9.5 \mathrm{~s})$, as discussed in Part I. ${ }^{[27]}$ Second, ion bombardment and the slow fluorination of exposed fresh backbone also reach a balance beyond $20 \mathrm{~cm}$ (9.5 s). As such, considering economic issues such as the utilization of feedstock gases and power consumption, under the base case conditions the optimal exposure time should be around $10 \mathrm{~s}$.

The model results for fractional surface coverages are compared to experiments for $26 \mathrm{~s}$ of treatment in Table $7 .{ }^{[27]}$ The general agreement is good, though the model underestimates the fraction of $\mathrm{CH}$ and $\beta-\mathrm{C}$ groups. Again, these discrepancies likely originate from the approximate means of addressing $\mathrm{F}$ atom diffusion to the under-layer and from the differences in the depths addressed between the ESCA and the model.

\section{$F_{2}$ Fraction}

In order to investigate process parameters that are not easily or inexpensively addressed experimentally, we varied the $F_{2}$ fraction, pressure, and power in the model. Reactant fluxes incident on the bottom side of the PP film as a function of position are shown in Figure $13 a-c$ while varying the $F_{2}$ fraction from 0.1 to 0.6 for a web speed of $9 \mathrm{~cm} \cdot \mathrm{s}^{-1}$ at 500 mTorr. The F-atom flux increases with increasing $F_{2}$ fraction. Since the power is held constant at $600 \mathrm{~W}$, the increases in fluxes are sub-linear with $\mathrm{F}_{2}$ fraction and begin to saturate for $\mathrm{F}_{2}$ fractions greater than 0.5. With increasing $F_{2}$ fraction, the reactor averaged $\left[\mathrm{F}^{-}\right]$increases from $1.2 \times 10^{10}$ to $3.0 \times 10^{10} \mathrm{~cm}^{-3}$ and the total positive ion density also increases to maintain charge neutrality. The end result is that the total ion flux incident on the film also increases and saturates. $\operatorname{Ar}(4 \mathrm{~s})$, $\mathrm{F}_{2}\left(\mathrm{C}^{1} \Sigma_{u}, \mathrm{H}^{1} \Pi_{u}\right)$, and $\mathrm{F}(3 \mathrm{~s})$ are the sources of VUV photons illuminating the PP film. With the increase in $\mathrm{F}_{2}$ fraction, the $\mathrm{Ar}$ inventory decreases and the $\mathrm{F}$ and $\mathrm{F}_{2}$ inventory increases so that the total photon flux is not a linear function of $\mathrm{F}_{2}$ fraction. The scaling of the $\mathrm{F} / \mathrm{C}$ ratio with $\mathrm{F}_{2}$ fraction is shown in Figure $13 \mathrm{~d}$. The $\mathrm{F} / \mathrm{C}$ ratio increases with $\mathrm{F}_{2}$ fraction commensurate with the increase in $\mathrm{F}$ atom fluxes and therefore also begins to saturate for $F_{2}$ fractions exceeding 0.5 .

Surface compositions of the PP film at the exit of the reactor as a function of increasing $F_{2}$ fraction are shown in Figure 14a. The coverages of $\mathrm{CF}_{2}$ and $\mathrm{CF}_{3}$ groups increase with increasing $\mathrm{F}_{2}$ fraction while coverages of $\mathrm{CH}$ and $\beta-\mathrm{C}$ groups decrease. These trends reflect the increase in the $\mathrm{F}$ atom flux. The surface coverage of $\mathrm{CF}$ remains largely unchanged. The fluorination of purely hydrocarbon sites to singly fluorinated sites producing $\mathrm{CF}$ and the fluorination of $\mathrm{CF}$ to $\mathrm{CF}_{2}$ (consuming $\mathrm{CF}$ ) are not particularly sensitive to the increase in $\mathrm{F}$ flux. The effect of the $\mathrm{F}_{2}$ fraction is largely on the rates of reaction and not to produce a fundamental change in the dominant reactions in the mechanism. 

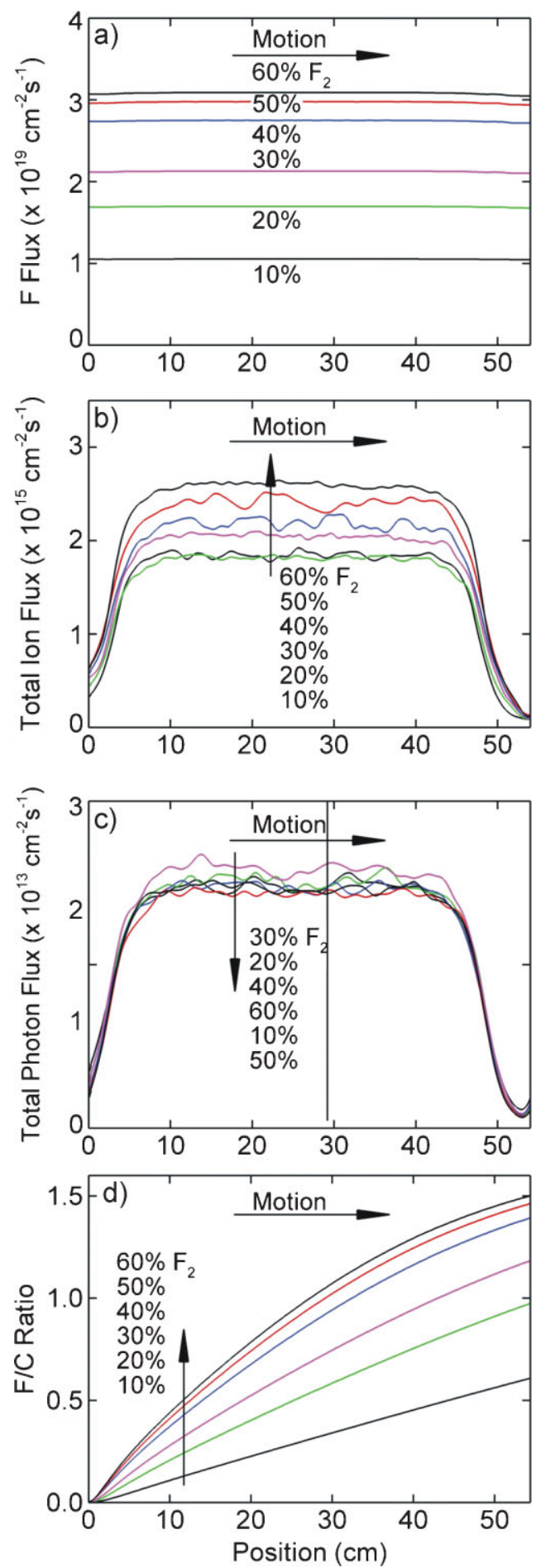

Figure 13. Fluxes incident on the bottom side of the PP film and corresponding $\mathrm{F} / \mathrm{C}$ ratios for $\mathrm{F}_{2}$ fractions of $10-60 \%$. The conditions are otherwise same as the base case $(500$ mTorr, $600 \mathrm{sccm}, 600 \mathrm{~W}$ at $10 \mathrm{MHz}$ and web speed of $\left.9 \mathrm{~cm} \cdot \mathrm{s}^{-1}\right)$. (a) $\mathrm{F}$ flux, (b) total ion flux, (c) total photon flux, and (d) F/C ratio. The $\mathrm{F} / \mathrm{C}$ ratio at the exit increases with increase in $\mathrm{F}_{2}$ fraction but does so sub-linearly with $F_{2}$ fraction.
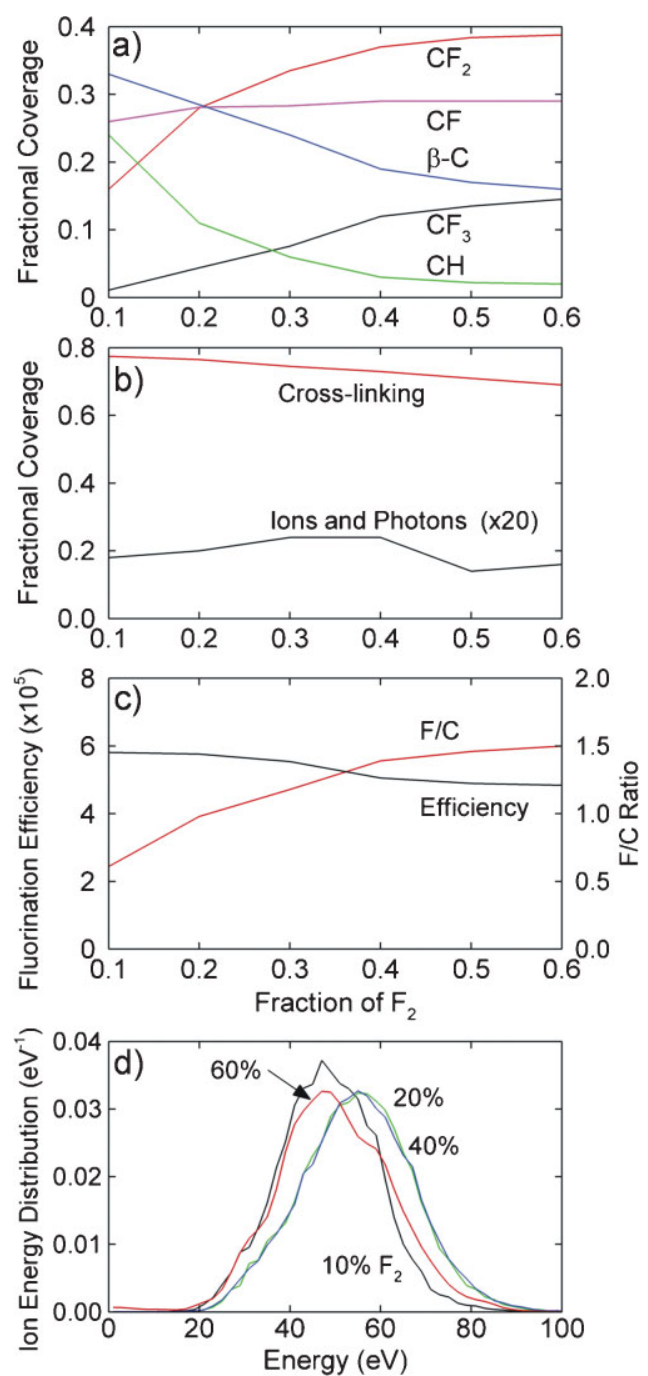

Figure 14. Surface compositions at the exit from the reactor on the bottom side of the film and fluorination efficiency as a function of $F_{2}$ fraction. The conditions are otherwise same as the base case $(500 \mathrm{mTorr}, 600 \mathrm{sccm}, 600 \mathrm{~W}$ at $10 \mathrm{MHz}$ and web speed of $9 \mathrm{~cm} \cdot \mathrm{s}^{-1}$ ). (a) Fractional coverage of functional groups, (b) fractional coverage of total PP unit sites modified by ion and photon bombardment, (c) $\eta$, fluorination efficiency and $\mathrm{F} / \mathrm{C}$ ratio, and (d) IEDs. $\eta$ decreases with increase in $F_{2}$ fraction because of the less efficient fluorination as $F / C$ increases.

The fractional coverages of the sum of PP unit sites modified by ion and photon bombardment and the sum of crosslinked unit sites are shown in Figure $14 \mathrm{~b}$ as a function of $\mathrm{F}_{2}$ fraction. Ion fluxes increase with $\mathrm{F}_{2}$ fraction, but the fraction of PP unit sites modified by ions and photons does not monotonically increase with $\mathrm{F}_{2}$ fraction as there are concurrent non-linear changes in the incident ion energies. For example, the ion energy distributions (IEDs) are shown in Figure 14d. The increase in $F_{2}$ flux with increase in $F_{2}$ fraction reduces the average lifetime of sites with free radicals by increasing the rate of passivation, thereby 
decreasing radical densities. At the same time, the rate of abstraction increases with increase in $\mathrm{F}$ atom flux, which increases the density of sites with free radicals. So increasing the $\mathrm{F}$ and $\mathrm{F}_{2}$ fluxes could either increase or decrease the density of polymer radicals depending on the state of fluorination of the surface. Since the rate of formation of crosslinked sites scales with the square of the density of radicals, the density of crosslinked sites could either increase or decrease with increase in $\mathrm{F}_{2}$ fraction. For our conditions, at the same fluorination state, the probabilities for F-atom addition are generally larger than those for $\mathrm{F}$ abstraction. Adding the passivation caused by $\mathrm{F}_{2}$, the total free radical inventory decreases with increase in $\mathrm{F}_{2}$ fraction and so the fraction of crosslinked sites decreases slightly with $\mathrm{F}_{2}$ fraction, as shown in Figure $14 \mathrm{~b}$.

To provide a relative estimate of the efficiency of the fluorination process, we define the fluorination efficiency as

$$
\eta=\frac{(\mathrm{F} / \mathrm{C})_{0}}{(\mathrm{~F} / \mathrm{C})_{m}} \times \frac{2\left[N_{\mathrm{S}}\right]}{\phi_{\mathrm{F}} \tau}
$$

where $(\mathrm{F} / \mathrm{C})_{0}$ is the ratio at the exit of the reactor and $(\mathrm{F} / \mathrm{C})_{m}$ is the maximum ratio, which for $\mathrm{PP}$ is 2 . $\left[N_{\mathrm{S}}\right]=6 \times 10^{15} \mathrm{~cm}^{-2}$ is the density of $\mathrm{H}$ sites (six $\mathrm{H}$ atoms per PP unit and $10^{15} \mathrm{~cm}^{-2}$ units), $\phi_{\mathrm{F}}$ the $\mathrm{F}$ atom flux, and $\tau$ is the exposure time to the plasma. The factor of two accounts for one $\mathrm{F}$ atom being required to abstract a $\mathrm{H}$ atom and one being required to passivate the resulting alkyl site. If the PP were exposed to a total fluence of $2\left[N_{S}\right] \mathrm{F}$ atoms and each atom either abstracted or passivated, the $\mathrm{F} / \mathrm{C}$ would be equal to 2. (Note that this approach overestimates $\eta$ since some passivation of radicals is performed by $\mathrm{F}_{2}$.) $\eta$ and the $\mathrm{F} / \mathrm{C}$ ratio at the exit from the reactor are shown in Figure 14c as a function of $\mathrm{F}_{2}$ fraction. The efficiencies are small, of the order of $10^{-5}-10^{-4}$, perhaps because of the non-unity reaction probabilities, values that decrease with an increase in $\mathrm{F} / \mathrm{C}$. The decrease in $\eta$ with increase in $F_{2}$ fraction is caused by this less-efficient fluorination as the $\mathrm{F} / \mathrm{C}$ ratio increases. So the increase in $\mathrm{F}$ atom flux that is obtained by increasing the $\mathrm{F}_{2}$ fraction is used somewhat less efficiently.

\section{Pressure}

Reactant fluxes as a function of position on the bottom side of the PP film are shown in Figure 15 while varying the reactor pressure from 100 to $700 \mathrm{mTorr}$ for $\mathrm{Ar} / \mathrm{F}_{2}=60 / 40$ and a web speed of $9 \mathrm{~cm} \cdot \mathrm{s}^{-1}$. With the increase in pressure, the fraction of the power deposition expended in bulk plasma processes (e.g., dissociation of $\mathrm{F}_{2}$ ) increases while the fraction of power dissipated by ion acceleration in the sheath decreases. Coupled with the increase in the total
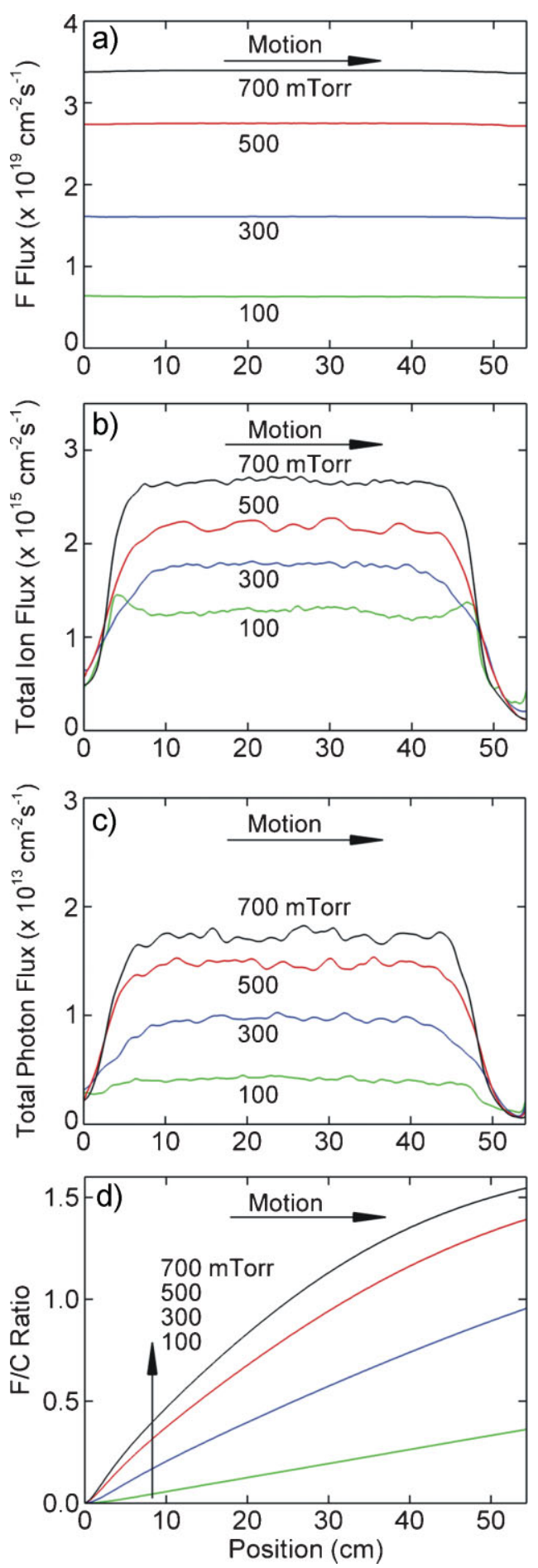

Figure 15. Fluxes incident on the bottom side of the PP film and corresponding F/C ratios for pressures of $100-700$ mTorr. The conditions are otherwise same as the base case $\left(\mathrm{Ar} / \mathrm{F}_{2}=60 / 40\right.$, $600 \mathrm{sccm}, 600 \mathrm{~W}$ at $10 \mathrm{MHz}$ and web speed of $\left.9 \mathrm{~cm} \cdot \mathrm{s}^{-1}\right)$. (a) $\mathrm{F}$ flux, (b) total ion flux, (c) total photon flux, and (d) F/C ratio. The $\mathrm{F} / \mathrm{C}$ ratio at the exit from the reactor increases with increase in pressure but begins to saturate at high pressures. 
inventory of $\mathrm{F}_{2}$, the reactant fluxes increase. With a constant power of $600 \mathrm{~W}$, the increase in reactant fluxes begins to saturate between 500 and 700 mTorr. Though ion and photon fluxes both increase with pressure, which could potentially remove $\mathrm{C}-\mathrm{F}$ bonding and so be detrimental to fluorination, the increase in the F-atom flux dominates. The end result is that the $\mathrm{F} / \mathrm{C}$ increases with increase in pressure, though sub-linearly, as shown in Figure 15d.

The surface composition at the exit of the film is shown in Figure $16 \mathrm{a}$ as a function of pressure. The increase in $\mathrm{F}$ atom flux with increasing pressure increases the surface coverages of $\mathrm{CF}_{n}(n=1-3)$ while decreasing the coverages of $\mathrm{CH}$ and $\beta-\mathrm{C}$ groups because of the more rapid fluorination. The increase in coverages of $\mathrm{CF}_{n}$ groups slows above 500 mTorr, commensurate with the saturation in the $\mathrm{F}$ atom flux.

The IEDs incident on the bottom side of the PP film are shown in Figure 16d for pressures from 100 to 700 mTorr. The IED at 700 mTorr loses the high-energy tail and is downshifted in energy compared to the IED at 100 mTorr. This downshift in energy results from the more frequent charge-exchange collisions in the sheath with increasing pressure, thereby producing a decrease in the probability of ion ablation. This decrease in probability partially offsets the increase in ion fluxes. The end result is that the sum of the total sites modified by ion and photon bombardment increases with pressure up to $500 \mathrm{mTorr}$, and then decreases at higher pressures, as shown in Figure 16b. The sum of coverages of crosslinked sites decreases with increase in pressure as the increase in $\mathrm{F}$ and $\mathrm{F}_{2}$ fluxes passivate free radical sites before they can crosslink, as shown in Figure 16b. Again, at higher pressures there is a slowing in the rate of fluorination with increase in $\mathrm{F} / \mathrm{C}$, which decreases the utilization of the larger fluxes and decreases $\eta$, as shown in Figure 16c.

\section{Power}

Reactant fluxes are shown in Figure 17 while varying the plasma power from 200 to $1500 \mathrm{~W}$ for a web speed of $9 \mathrm{~cm} \cdot \mathrm{s}^{-1}$. While keeping $\mathrm{Ar} / \mathrm{F}_{2}=60 / 40$, the dissociation fraction of $\mathrm{F}_{2}$ increases from 0.14 at $200 \mathrm{~W}\left(0.09 \mathrm{~W} \cdot \mathrm{cm}^{-2}\right.$ of electrode area or $0.037 \mathrm{~W} \cdot \mathrm{cm}^{-3}$ of inter-electrode volume) to 0.35 at $1500 \mathrm{~W}\left(0.71 \mathrm{~W} \cdot \mathrm{cm}^{-2}\right.$ of electrode area or $0.28 \mathrm{~W} \cdot \mathrm{cm}^{-3}$ of inter-electrode volume). The increase in $\mathrm{F}$ flux is less than linear with power as a consequence of an increasing proportion of the power being dissipated by ion acceleration. Commensurate with the increase in $\mathrm{F}$ atom flux (which increases $\mathrm{F} / \mathrm{C}$ ) with increasing power, the ion and photon fluxes (which decrease or slow the rate of increase in $\mathrm{F} / \mathrm{C}$ ) also increase.

With the increase in rf voltage with increasing power, the ion energies bombarding the PP film also increase, as shown
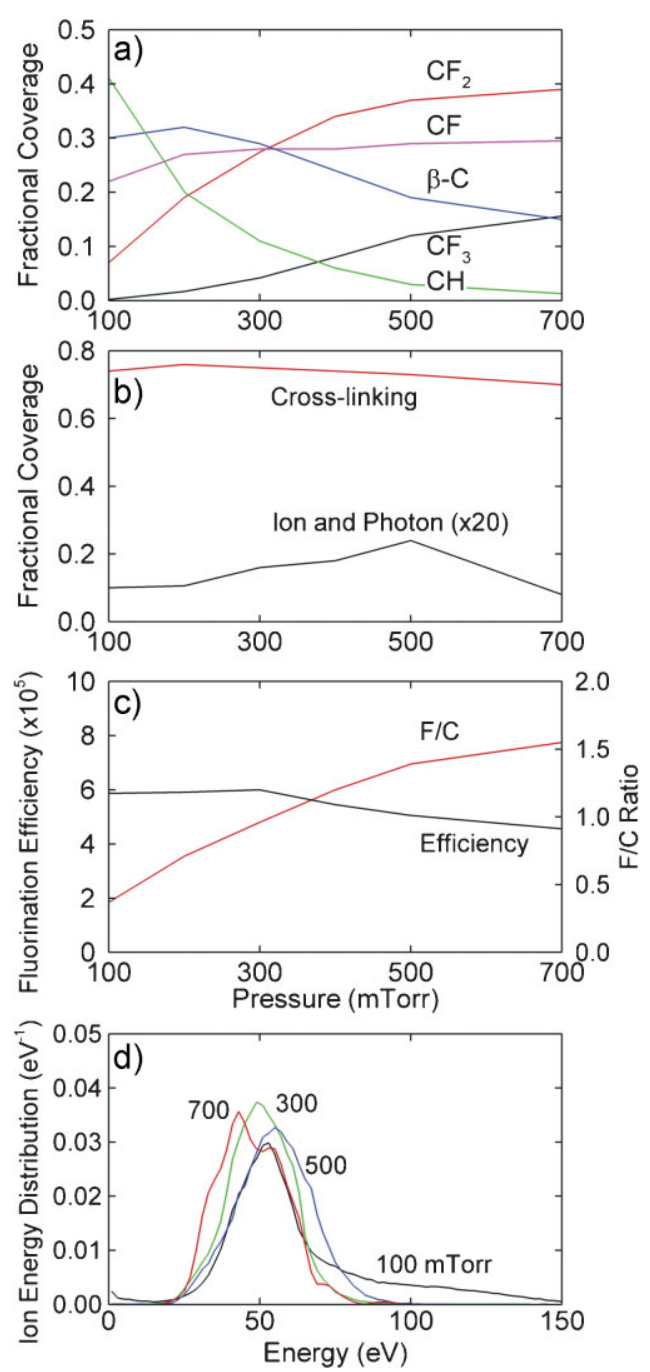

Figure 16. Surface compositions at the exit from the reactor on the bottom side of the film and fluorination efficiency as a function of pressure. The conditions are otherwise same as the base case $\left(\mathrm{Ar} / \mathrm{F}_{2}=60 / 40,600 \mathrm{sccm}, 600 \mathrm{~W}\right.$ at $10 \mathrm{MHz}$ and web speed of $\left.9 \mathrm{~cm} \cdot \mathrm{s}^{-1}\right)$. (a) Fractional coverage of functional groups, (b) fractional coverage of total PP unit sites modified by ion and photon bombardment, (c) $\eta$, fluorination efficiency and F/C ratio, and (d) IEDs. For pressures $>500$ mTorr, the sum of PP unit sites modified by ion and photon bombardment decreases with increase in pressure as a result of decreasing ion-ablation processes.

in Figure 18d. The resulting increase in the probability for ion ablation together with the increase in ion fluxes compete with the increase in fluorination produced by the higher $\mathrm{F}$ atom flux. This competition contributes to the saturation of the $\mathrm{F} / \mathrm{C}$ ratio with increase in power above $1000 \mathrm{~W}$, as shown in Figure 17d.

Surface coverages of functional groups at the exit are shown in Figure 18a as a function of power. The sum of coverages of $\mathrm{CH}$ and $\beta-\mathrm{C}$ decreases from 0.3 at $200 \mathrm{~W}$ to 0.17 at $1500 \mathrm{~W}$, in response to the increase in F flux, which more 

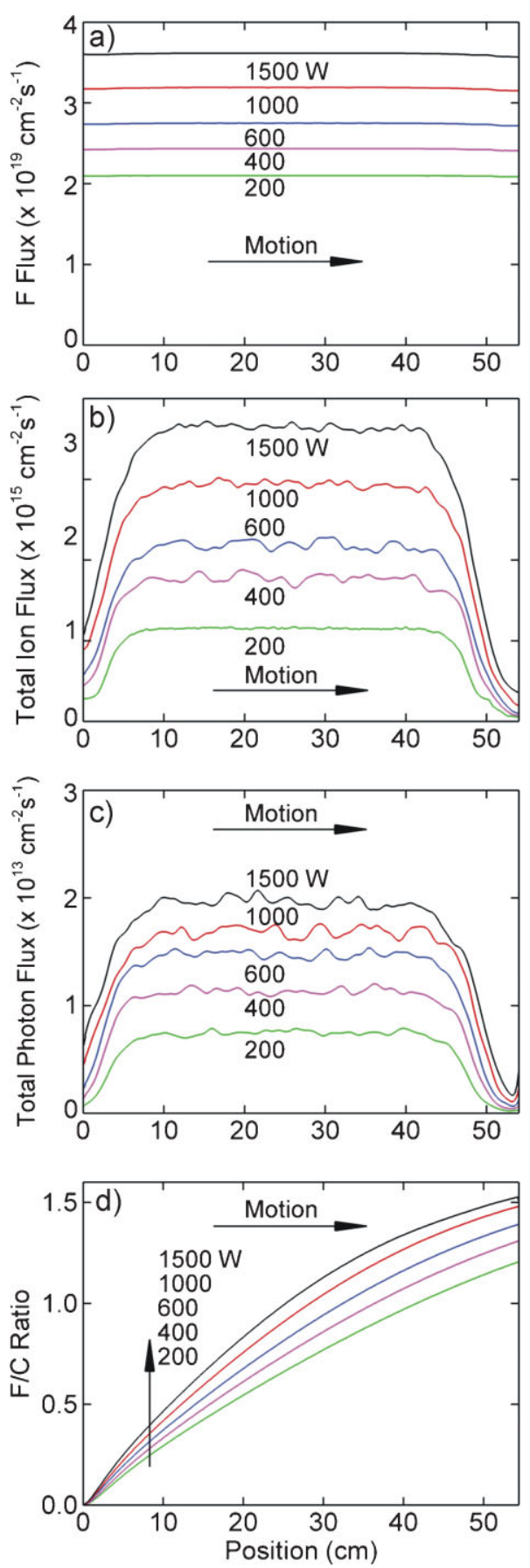

Figure 17. Fluxes incident on the bottom side of the PP film and corresponding F/C ratios for powers of $100-1500 \mathrm{~W}$. The conditions are otherwise the same as the base case $\left(\mathrm{Ar} / \mathrm{F}_{2}=60 / 40\right.$, $600 \mathrm{sccm}, 500 \mathrm{mTorr}$ at $10 \mathrm{MHz}$ and web speed of $9 \mathrm{~cm} \cdot \mathrm{s}^{-1}$ ). (a) F flux, (b) total ion flux, (c) total photon flux, and (d) F/C ratio.

rapidly abstracts and passivates the $-\mathrm{CH}$ sites. As the $\mathrm{F}$ flux increases by only a factor of 1.7 from 200 to $1500 \mathrm{~W}$ while the ion flux increases by a factor of 3.5 , the coverages of $\mathrm{CF}_{2}$ and $\mathrm{CF}_{3}$ groups increase only moderately with increasing power.
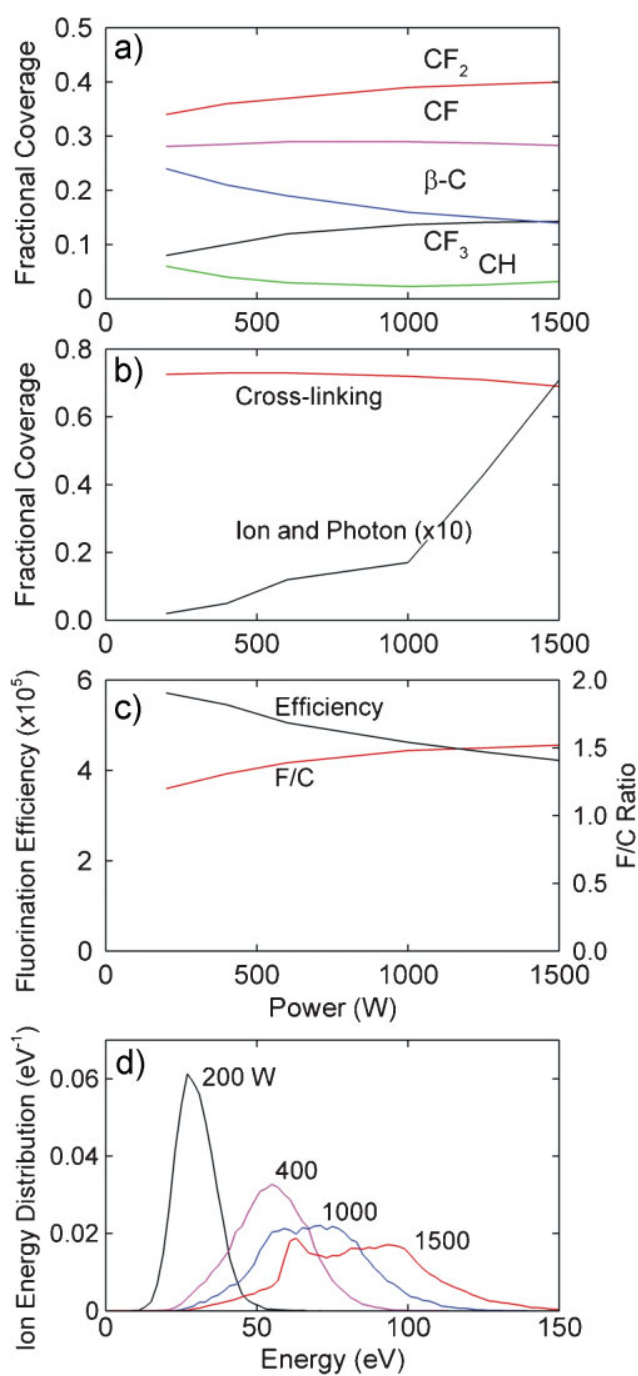

Figure 18. Surface compositions at the exit from the reactor on the bottom side of the film and fluorination efficiency as a function of power. The conditions are otherwise same as the base case $\left(\mathrm{Ar} / \mathrm{F}_{2}=60 / 40,600 \mathrm{sccm}, 500 \mathrm{mTorr}\right.$ at $10 \mathrm{MHz}$ and web speed of $\left.9 \mathrm{~cm} \cdot \mathrm{s}^{-1}\right)$. (a) Fractional coverage of functional groups, (b) fractional coverage of total PP unit sites modified by ion and photon bombardment, (c) $\eta$, fluorination efficiency and F/ $C$ ratio, and (d) IEDs.

With the increase in power, more sites are modified by ion and photon bombardment (primarily above $1000 \mathrm{~W}$ ), while the fraction of sites that are crosslinked only moderately decreases, as shown in Figure 18b. The increase in ion and photon modified sites is largely caused by the increase in ion fluxes and energy, which alone should increase the proportion of crosslinked sites. However, the increase in F-atom fluxes is sufficient to offset the increased rate of free radical site production and crosslinking decreases. Above $1000 \mathrm{~W}$, the coverages of ionablated sites increases rapidly as a result of the increase in ion energy. These effects partly contribute to the decrease in 
fluorination efficiency, as also shown in Figure 18c. The less efficient fluorination at higher $\mathrm{F} / \mathrm{C}$ ratios with increasing power also contributes to the decrease in $\eta$.

\section{Conclusion}

The low-pressure plasma fluorination of PP in CCPs sustained in $\mathrm{Ar} / \mathrm{F}_{2}$ mixtures was computationally investigated. The surface reaction mechanism includes a hierarchy of fluorination reactions (abstraction and addition), ion sputtering, photon activated process, and crosslinking. Good agreement was obtained between the model and experimental results for the $\mathrm{F} / \mathrm{C}$ ratio and the fraction of functional groups.

The sequence of hydrogen abstraction and passivation by $\mathrm{F}$ and $\mathrm{F}_{2}$ with rates slowed by steric hindrance and deactivation with increasing F/C generally explains the experimentally observed trends. Concurrent to the passivation of free radical sites (produced by $\mathrm{H}$ abstraction) by $\mathrm{F}$ and $F_{2}$ fluxes, which creates fluorine-containing functionalities, adjacent free radicals will also crosslink. This crosslinking of up to $10 \%$ of the carbon atoms partially accounts for the lack of full fluorination, i.e., a $\mathrm{F} / \mathrm{C}<2$, even after long plasma exposure. Crosslinking is most likely on $\mathrm{C}_{\mathrm{P}}$ sites as they protrude from the PP chain and contain more $\mathrm{C}-\mathrm{H}$ bonding that can potentially lead to crosslinks. The elimination of these sites, which potentially could become $\mathrm{CF}_{3}$ sites, and the effective conversion of $\mathrm{C}_{\mathrm{P}}$ sites to $\mathrm{C}_{\mathrm{S}}$ sites, increases the proportion of $\mathrm{CF}_{2}$ functionalitiy. As the PP film is electrically floating in the plasma and charge-exchange collisions further degrade the IEADs in energy, ablation of fluorinated segments by ion sputtering is not appreciable for exposure time less than $30 \mathrm{~s}$ for powers of $<0.7 \mathrm{~W} \cdot \mathrm{cm}^{-2}$. The ablation is most efficient at removing $\mathrm{CH}_{3}$ groups (including fluorinated states) because of lower surface binding energy. VUV illumination does not produce major changes in surface composition for exposure times less than $30 \mathrm{~s}$ for powers $<0.7 \mathrm{~W} \cdot \mathrm{cm}^{-2}$ because of the relatively low magnitude of photon fluxes. However, the cumulative effects of decreasing rates of fluorination as F/C increases, coupled with ion sputtering and VUV photolysis, reduces the efficiency of fluorination for long exposure times or high powers.

This modeling study and the companion experimental investigation have provided opportunities to quantify complex plasma functionalization processes. ${ }^{[27]}$ Although the numerical values mentioned below are particular to the conditions investigated, they nevertheless do provide some insights to these processes.

(i) For the base case conditions, at one point during the functionalization $9 \%$ of the PP carbon atoms in the surface layers are in the form of free radicals.
The presence of so many radicals that have not yet reacted with $\mathrm{F}$ atoms and $\mathrm{F}_{2}$ molecules is likely the reason why crosslinking is so prevalent.

(ii) After only $1.1 \mathrm{~s}$ of processing, $97 \%$ of the PP units have at least one $\mathrm{F}$ atom added. By the end of the reactor, $96 \%$ of the surface $\mathrm{H}$ atoms have been removed.

(iii) Excluding PP units involved in some type of crosslinking, at the exit of the reactor in the base case only $7 \%$ of the surface is fully fluorinated. At the same time, about $70 \%$ of the PP units are involved with crosslinking at the exit of the reactor. About $10 \%$ of all of the PP units are crosslinked through the tertiary C, which leads to the large $\beta$-shift $C$ in the final ESCA spectra.

(iv) Only about 1\% of the PP units left on the surface at the exit of the reactor have been involved in an ion-impact reaction. As such, much of the crosslinking results from radical reactions leading to cross-linking early during plasma exposure.

Acknowledgements: This work was supported by the $3 M$ Company Corporate Research Process Laboratory.

Received: July 10, 2009; Revised: November 13, 2009; Accepted: November 18, 2009; DOI: 10.1002/ppap.200900114

Keywords: capacitively coupled; films; fluorination; modeling; polymer modification; surface composition

[1] M. Strobel, S. Corn, C. S. Lyons, G. A. Korba, J. Polym. Sci., Part A: Polym. Chem. 1985, 23, 1125.

[2] I. H. Loh, M. Klausner, R. F. Baddour, R. E. Cohen, Polym. Eng. Sci. 1987, 27, 861.

[3] G. Kranz, R. Luschen, T. Gesang, V. Schlett, O. D. Hennemann, W. D. Stohrer, Int. J. Adhes. Adhes. 1994, 14, 243.

[4] W. T. Miller, S. D. Koch, J. Am. Chem. Soc. 1957, 79, 3084.

[5] T. Yagi, A. E. Pavlath, J. Appl. Polym. Sci. 1984, 38, 201.

[6] N. de Geyter, R. Morent, L. Gengembre, C. Leys, E. Payen, S. Van Vlierberghe, E. Schacht, Plasma Chem. Plasma Process. 2008, 28, 289.

[7] M. Anand, R. E. Cohen, R. F. Baddour, Polymer 1981, 22, 370.

[8] D. Barton, J. W. Bradley, K. J. Gibson, D. A. Steele, R. D. Short, J. Phys. Chem. B 2000, 104, 7150.

[9] G. A. Corbin, R. E. Cohen, R. F. Baddour, Polymer 1982, 23, 1546.

[10] M. Anand, R. E. Cohen, R. F. Baddour, ACS Symp. Ser. 1981, 162, 353.

[11] J. Hopkins, J. P. S. Badyal, J. Phys. Chem. 1995, 99, 4261.

[12] V. Stelmashuk, H. Biederman, D. Slavinska, M. Trchova, P. Hlidek, Vacuum 2004, 75, 207.

[13] H. Biederman, V. Stelmashuk, I. Kholodkov, A. Choukourov, D. Slavinska, Surf. Coat. Technol. 2003, 174, 27.

[14] H. Biederman, Vacuum 2000, 59, 594. 
[15] R. Wilken, A. Hollander, J. Behnisch, Plasmas Polym. 2002, 7, 19.

[16] A. Hollander, J. E. Klemberg-Sapieha, M. R. Wertheimer, J. Polym. Sci., Part A 1995, 33, 2013.

[17] C. M. Chan, T. M. Ko, Surf. Sci. Rep. 1996, 24, 1.

[18] F. D. Egitto, L. J. Matienzo, Polym. Degrad. Stab. 1990, 30, 293.

[19] F. D. Egitto, Pure Appl. Chem. 1990, 62, 1699.

[20] V. N. Vasilets, A. V. Kuznetsov, V. I. Sevastianov, J. Biomed. Mater. Res. 2004, 69A, 428.

[21] G. A. Corbin, R. E. Cohen, R. F. Baddour, Macromolecules 1985, 18, 98.

[22] Yu. I. Dorofeev, V. E. Skurat, Russ. Chem. Rev. 1982, 51 , 527.

[23] Yu. A. Dorofeev, V. E. Skurat, Dokl. Akad. Nauk SSSR 1978, 243, 1479.

[24] V. Skurat, Nucl. Instrum. Methods Phys. Res., B 2003, $208,27$.

[25] M. Ono, H. Yamane, H. Fukagawa, S. kera, D. Yoshimura, K. K. Okudaira, E. Morikawa, K. Seki, N. Ueno, Nucl. Instrum. Methods Phys. Res., B 2005, 236, 377.

[26] V. E. Skurat, A. P. Nikiforov, High Perform. Polym. 2004, 16, 339.

[27] S. Kirk, M. Strobel, C.-Y. Lee, S. J. Pachuta, M. Prokosch, H. Lechuga, M. Jones, C. Lyons, S. Degner, Y. Yang, M. J. Kushner, Plasma Processes Polym. DOI: 10.1002/ppap.200900111.

[28] M. J. Kushner, J. Appl. Phys. 2003, 94, 1436.

[29] J. Lu, M. J. Kushner, J. Vac. Sci. Technol., A 2001, 19, 2652.

[30] K. Rajaraman, M. J. Kushner, J. Phys. D 2004, 37, 1780.

[31] D. Zhang, M. J. Kushner, J. Vac. Sci. Technol., A 2000, 18, 2661.

[32] D. Briggs, Surface Analysis of Polymers by XPS and Static SIMS, Cambridge University Press, Cambridge 1998.

[33] R. Dorai, M. J. Kushner, J. Phys. D 2003, 36, 666.

[34] G. C. Fettis, J. H. Knox, A. F. Trotman-Dickenson, Can. J. Chem. 1960, 38, 1643.

[35] P. S. Fredricks, J. M. Tedder, J. Chem. Soc. 1960, 144.

[36] A. M. B. Giessing, A. Feilberg, T. E. Mogelberg, J. Sehested, M. Bilde, T. J. Wallington, O. J. Nielsen, J. Phys. Chem. 1996, 100, 6572.
[37] Y. D. Gao, R. G. MacDonald, J. Phys. Chem. A 2006, 110, 977.

[38] A. Goldbach, F. Temps, H. G. Wagner, B. Bunsenges Phys. Chem. 1990, 94, 1367.

[39] L. Wang, V. V. Kislov, A. M. Mebel, X. M. Yang, X. Y. Wang, Chem. Phys. Lett. 2005, 406, 60.

[40] C. Moore, I. W. M. Smith, J. Chem. Soc. Faraday Trans. 1995, 91 , 3041.

[41] I. C. Plumb, K. R. Ryan, Plasma Chem. Plasma Process. 1986, 6, 11.

[42] T. L. Pollock, W. E. Jones, Can. J. Chem. 1973, 51, 2041.

[43] A. Persky, Chem. Phys. Lett. 2003, 380, 286.

[44] J. F. Ziegler, http://www.srim.org.

[45] F. L. Nesbitt, R. P. Thorn, W. A. Payne, D. C. Tardy, J. Phys. Chem. A 1999, 103, 4470.

[46] M. Hayashi, T. Nimura, J. Appl. Phys. 1983, 54, 4879.

[47] W. L. Morgan (private communication), Kinema Software, http://www.kinema.com.

[48] K. Tachibana, Phys. Rev. A 1986, 34, 1007.

[49] D. Rapp, P. Englander-Golden, J. Chem. Phys. 1965, 43, 1464.

[50] R. H. McFarland, J. D. Kinney, Phys. Rev. 1965, 137, 1058.

[51] I. P. Zapesochnyi, Y. N. Semenyuk, A. I. Dashchenko, A. E. Imre, A. I. Zapesochny, JETP Lett. 1984, 39, 141.

[52] L. Vriens, Phys. Lett. 1964, 8, 260.

[53] M. Diegelmann, K. Hohla, F. Rebentrost, K. L. Kompa, J. Chem. Phys. 1982, 76, 1233.

[54] K. Sasaki, Y. Kawai, K. Kadota, Rev. Sci. Instrum. 1999, 70, 76.

[55] G. M. Lawrence, Phys. Rev. A 1968, 175, 40.

[56] A. N. Klucharev, V. Vujnovic, Phys. Rep. 1990, 185, 55.

[57] H. W. Ellis, R. Y. Pai, E. W. McDaniel, E. A. Mason, L. A. Viehland, At. Data Nucl. Data Tables 1976, 17, 177.

[58] G. I. Font, W. L. Morgan, G. Mennenga, J. Appl. Phys. 2002, 91, 3530.

[59] R. E. Olson, J. R. Peterson, J. Moseley, J. Chem. Phys. 1970, 53, 3391.

[60] P. Ho, J. E. Johannes, R. J. Buss, E. Meeks, J. Vac. Sci. Technol., A 2001, 19, 2344.

[61] C. J. Ultee, Chem. Phys. Lett. 1977, 46, 366. 